\title{
Application of a semi-detailed soot modeling approach for conventional and low temperature diesel combustion - Part I: Model Performance
}

\author{
Gokul Vishwanathan ${ }^{\mathrm{a}, 1}$ and Rolf D. Reitz \\ Engine Research Center, Department of Mechanical Engineering, University of Wisconsin-Madison, \\ Madison, WI-53706, USA. Email: 'agkulvishwanathan@gmail.com; reitz@engr.wisc.edu
}

\begin{abstract}
In the present study a previously developed soot model has been tested extensively for conventional and low temperature diesel combustion engine simulations. The soot model framework, which was implemented in the Computational Fluid Dynamics (CFD) code KIVA-CHEMKIN, is based on four fundamental steps, viz., soot inception through a four ring polycyclic aromatic hydrocarbon species, soot surface growth through acetylene and benzene, soot coagulation, and oxygen and $\mathrm{OH}$-induced soot oxidation. The proposed model can be used not only for soot mass predictions, but also for soot number density and soot particle diameter predictions. Diesel combustion was simulated using reduced n-heptane/primary reference fuel (PRF) chemistry mechanisms and a reduced polycyclic aromatic hydrocarbon (PAH) chemistry mechanism, while the n-heptane chemistry mechanism was used for modeling constant volume nheptane combustion. Soot model performance was evaluated by comparing the model predictions with available constant volume combustion chamber optical diagnostic experiments, optical engine in-cylinder soot data, and a light-duty single cylinder metal engine-out smoke data. In particular, a variety of combustion regimes were tested, including conventional diesel, premixed charge compression ignition (PCCI), and high exhaust gas recirculation (EGR) low temperature combustion (LTC). In general, the model was able to predict well the trends in soot mass over the range of operating conditions. With increasing degree of premixing, the model was able to predict relatively lower soot concentrations compared to diffusion combustion. In terms of soot particle diameter, the model computed particle size was seen to increase with increasing simulated EGR when the ambient oxygen concentration was varied from $21 \%$ to $8 \%$ by volume and with increasing in-cylinder density $\left(14.8 \mathrm{~kg} / \mathrm{m}^{3} \mathrm{vs} .30 \mathrm{~kg} / \mathrm{m}^{3}\right.$ at the same in-cylinder $\mathrm{O}_{2}$ level)
\end{abstract}

\footnotetext{
${ }^{1}$ Corresponding author. The corresponding author is currently employed at Booz Allen Hamilton
} 
under steady-state constant volume combustion conditions. It is also observed from the optical and metal engine studies that the soot particle size is larger for high temperature combustion conditions that are marked with high soot formation rates during the combustion process and may or may not lead to smaller particles at exhaust valve opening (EVO) depending on the oxidation rates. The soot size for LTC is generally lower through-out the combustion process including EVO conditions. All but one data-point show uni-modal type soot particle size distribution with respect to both soot mass and particle number.

\section{Keywords}

CFD; Soot model; Polycyclic aromatic hydrocarbon (PAH) chemistry; Low temperature combustion; Combustion chemistry; PRF mechanism

\section{Introduction}

Increasingly stringent pollution mandates have necessitated further study of gasoline and diesel combustion fundamentals. Particularly, mitigating emissions of NOx and soot in diesel engines has been a long-standing challenge for the internal combustion engine community. After-treatment devices such as selective catalytic reduction (SCRs), NOx absorbers and diesel particulate filters (DPFs) are actively being employed to control regulated pollutant emissions, but the conversion efficiency, durability, backpressure, and the need for thermal management strategies are some of the challenges posed by these devices. Also, with recent emphasis on corporate average fuel economy (CAFE) and greenhouse gas (GHG) standards, the spotlight in engine research has lately transitioned from emissions to fuel economy. Hence there exists a need to probe alternative combustion strategies, not only to reduce emissions within the engine combustion chamber, but also from an efficiency standpoint. These advanced combustion strategies are significantly different than conventional combustion strategies for both spark-ignited (SI) and compression-ignited (CI) engines. Particularly for diesel engines, strategies such as homogeneous charge compression ignition (HCCI), achieved by significantly early injections, premixed charge compression ignition (PCCI), possibly with two injections (one early and one conventional), and low temperature combustion (LTC) with heavy amounts of exhaust gas recirculation (EGR) are being explored [1,2]. Figure 1, reproduced from Akihama et al. [1] and modified here (shown in bold text) for illustration purposes, shows the combustion regimes in the classic equivalence ratio-temperature $(\Phi-T)$ map. The modifications were based on the generic $\Phi$-T plot 
shown in Tree and Svensson [2], which are derived from the experimental observations of Pickett and Siebers [3] in a constant volume spray vessel. These regimes of combustion are very different compared to conventional diesel diffusion combustion, which significantly alters the mechanisms of pollutant formation processes. As seen in Figure 1, the drive has been to operate the engine either between the soot and NOx peninsulas or at much lower temperatures, which provides a wider operating range and hence is desirable. Soot formation can be avoided either by operating at lower temperatures $(<1800 \mathrm{~K})$ or higher temperatures $(>$ $2600 \mathrm{~K}$ ) or lower local equivalence ratios $(<2)$, but lower NOx warrants lower in-cylinder temperatures. Points 1 (a) and 1 (b) refer to high EGR LTC $\left(\sim 10 \%\right.$ ambient $\left.\mathrm{O}_{2}\right)$ with a small nozzle diameter $(\sim 50 \mu)$ for enhanced fuel-air mixing. The fuel jet core is represented by point $1 \mathrm{a}(\Phi>1$ and low temperature) while the flame sheet is represented by $1 \mathrm{~b}(\Phi \sim 1$ and high temperature). As the nozzle diameter is small, which enhances atomization, the entrained air amount is higher, which inhibits soot formation in the fuel jet core. In the flame sheath region the high EGR helps to keep the temperatures low and hence lower in-cylinder NOx is achieved. Point 2 corresponds to an ambient temperature of $850 \mathrm{~K}$ with higher oxygen content $\left(21 \% \mathrm{O}_{2}\right)$ and also using small nozzle diameters $(\sim 50 \mu)$. This corresponds to low temperature lean combustion. PCCI falls closer to point 2, which is generally accomplished with multiple injections where the overall equivalence ratio could be much less than local equivalence ratios. The ordinate of the point 'PCCI' in the figure represents the local equivalence ratio. Point 3 refers to high EGR operation $\left(\sim 8 \%\right.$ ambient $\left.\mathrm{O}_{2}\right)$ with a production feasible nozzle diameter $(\sim 180 \mu)$ while operating with an oxygenated fuel, which produces the same result of low NOx and low soot.

This discussion indicates that there are multiple ways of obtaining low NOx and low soot, at least from a scientific standpoint, and the current techniques rely on longer ignition delay combustion strategies to allow more time for fuel-air mixing. From a modeling perspective, predicting emissions for low NOx-low soot combustion necessitates less empirical and more physically driven pollutant models that can reasonably replicate the formation and oxidation kinetics over a wide range of operation. Particularly, soot modeling for conventional diesel combustion has been a long standing research subject and, with newer combustion regimes, soot models are further challenged. Also, to prevent the possibility of allowing ultra-fine particles from escaping into the atmosphere, future US, Japan and European standards aim at mandating particulate 
number (PN) (Johnson [4]), and thus model predictions of engine-out soot particle size and number density along with soot mass have gained increasing importance.

Finally, the last piece of the modeling puzzle is the fuel itself. Due to limited resources of fossil fuels and with the growing momentum for their conservation, dual fuel combustion such as pilot diesel ignited natural gas, reactivity controlled compression ignition (RCCI) [5], and use of alternative fuels such as E85 ( $85 \%$ by volume of ethanol and $15 \%$ by volume of gasoline) and biodiesel are also being explored for diesel and gasoline engines. The pathways of soot formation differ from one fuel to another depending upon the fuel composition. Regular pump gasoline or diesel may have anywhere between $20 \%-32 \%$ aromatics by volume, which are also major contributors to soot formation, in addition to soot formation due to fuel chain breakdown. However, fuels such as biodiesel (mainly composed of fatty acid esters) and natural gas (mainly composed of methane) do not have fuel aromatics and hence the soot formation is directly a function of the fuel breakdown chemistry. Thus, newer emission and fuel efficiency standards along with the continued focus on exhaust particulate reduction motivate the drive toward newer in-cylinder engine combustion strategies and alternative fuels. Consequently, the modeling thrust is to reduce empirical approaches and replace them with more physics-based detailed and versatile combustion and emission models.

In the present work, the soot model of Ref. [8] implemented in the 3-D CFD code KIVACHEMKIN was applied to study advanced diesel combustion modes, including conventional diesel combustion, high-EGR diesel LTC and diesel PCCI. Also, the model predictions of soot mass were compared with available experimental data and model predictions of soot diameter were qualitatively evaluated for each combustion mode. The computational mesh, spray, turbulence, and other sub-models are the same as used in Vishwanathan and Reitz [8]. 


\section{Model framework}

\subsection{Chemistry mechanisms}

\subsubsection{Fuel and lower carbon chemistry}

Two separate chemistry mechanisms were used in the present study. The first mechanism (Mech-1) comprised 37 species and 180 reactions, and is an n-heptane mechanism that was applied for constant volume $\mathrm{n}$-heptane combustion. The second mechanism is a reduced primary reference fuel (PRF) mechanism ( $\mathrm{Ra}$ and Reitz [7]), which was found to be more suitable for diesel engine combustion simulations (Mech-2). Mech-2 comprised 40 species and 280 reactions. Both these mechanisms were previously used by Vishwanathan and Reitz [8]. Throughout this work diesel was modeled with the fuel properties of tetradecane $\left(\mathrm{C}_{14} \mathrm{H}_{30}\right)$ [8].

\subsubsection{PAH chemistry using $\mathrm{Xi}$ and Zhong mechanism}

The reduced PAH mechanism was obtained from Xi and Zhong [9] and integrated with the above two mechanisms. The first aromatic ring formation, i.e., $\mathrm{A}_{1}$ takes place through the propargyl radical $\left(\mathrm{C}_{3} \mathrm{H}_{3}\right)$. Higher PAHs are formed through the hydrogen-abstraction and carbon-addition (HACA) mechanism (Frenklach and Wang [10]). The nomenclature adopted for representing PAHs (e.g., $\mathrm{A}_{1}=$ benzene, $\mathrm{A}_{2}=$ naphthalene, $\mathrm{A}_{3}=$ Phenanthrene, and $\mathrm{A}_{4}=$ Pyrene) is common in the literature, where A denotes a mono- or poly-aromatic species and the suffix denotes the number of fused aromatic rings. This PAH mechanism (PAH-1) was comprised 21 species and 52 reactions.

\subsection{Soot Model}

The soot model was implemented in the 3-D CFD code KIVA-CHEMKIN [6] and published by Vishwanathan and Reitz [8] and Vishwanathan [11]. The present modeling framework is summarized as follows:

a) Soot inception through $\mathbf{A}_{4}$ : 
$\mathrm{C}_{16} \mathrm{H}_{10}\left(\mathrm{~A}_{4}\right) \stackrel{\dot{\mathrm{R}}_{1}}{\rightarrow} \rightarrow 16 \mathrm{C}(\mathrm{s})+5 \mathrm{H}_{2}, \dot{\mathrm{R}}_{1}=\mathrm{k}_{1} \cdot\left[\mathrm{A}_{4}\right], \mathrm{k}_{1}=2000\left\{\mathrm{~s}^{-1}\right\}$

$\left[\mathrm{A}_{4}\right]$ represents the concentration of $\mathrm{A}_{4} \mathrm{in} \mathrm{mol} \mathrm{cm}^{-3}$. [ ] indicates concentration of species.

\section{b) $\mathrm{C}_{2} \mathrm{H}_{2}$ assisted surface growth:}

$s+\mathrm{C} 2 \mathrm{H} 2 \mathrm{R} 23 \mathrm{Cs}+\mathrm{H} 2, \mathrm{R} 2=\mathrm{k} 2 \cdot \mathrm{C} 2 \mathrm{H} 2$,

$\mathrm{k} 2=9.0 \cdot 104 \cdot \exp -12100 \mathrm{~T} \cdot \mathrm{S} \mathrm{s}-1, \mathrm{~S}=\pi \mathrm{dp} 2 \cdot \mathrm{N} \mathrm{cm}-1, \mathrm{dp}=6 \mathrm{Y} \operatorname{cs} \rho \pi \rho \operatorname{cs} \mathrm{N} 13\{\mathrm{~cm}\}$

$S$, is the soot surface area per unit volume, which can be obtained from the particle size, $d_{p}, Y_{c(s)}$ is the soot mass fraction, $\rho$ is the ambient density, $\rho_{\mathrm{c}(\mathrm{s})}$ is the soot density for which the density of graphite $\left(2.0 \mathrm{~g} \mathrm{~cm}^{3}\right)$ is used in this study, and $\mathrm{N}$ is the soot number density in particles $\mathrm{cm}^{-3}$. For each computational cell, the model would predict a unique value of soot species density and soot number density, and hence a soot diameter for each cell. This diameter can be viewed as a local number-averaged soot particle size. Hence, the model is locally mono-disperse (on a computational cell basis) but the diameter can vary from one computational cell to another.

\section{c) Soot coagulation:}

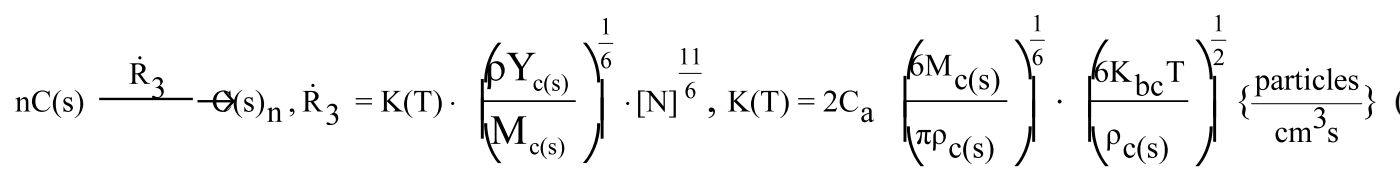

where, $\mathrm{M}_{\mathrm{c}(\mathrm{s})}$ is the molecular weight of carbon $\left(12.0 \mathrm{~g} \mathrm{~mol}^{-1}\right), \mathrm{T}$ is the temperature of the CFD cell and $\mathrm{K}_{\mathrm{bc}}$ is Boltzmann's constant $\left(1.38054 \cdot 10^{-16} \mathrm{erg} \mathrm{K}^{-1}\right)$. The constant $\mathrm{C}_{\mathrm{a}}$ is the agglomeration constant for which a value of 9.0 was used in this study. The particle size $d_{p}$ is the effective particle diameter accounting for soot coagulation and is termed the 'spherical agglomerate size'. The primary particle size can be obtained by equating the coagulation term to zero.

\section{d) Soot oxidation through Nagle-Strickland and Constable model [12]:}




$$
\begin{aligned}
& \mathrm{C}(\mathrm{s})+\frac{1}{2} \mathrm{O}_{2} \frac{\dot{\mathrm{R}}_{4}}{\mathrm{C}} \oplus, \dot{\mathrm{R}}_{4}=\frac{12}{\mathrm{M}_{\mathrm{c}(\mathrm{s})}} \cdot\left(\left(\frac{\mathrm{K}_{\mathrm{A}} \mathrm{P}_{\mathrm{O}_{2}}}{\mathrm{l}_{\mathrm{Z}} \mathrm{K}_{\mathrm{P}}}\right) \cdot \mathrm{x}+\mathrm{K}_{\mathrm{B}} \mathrm{P}_{\mathrm{O}_{2}} \cdot(1-\mathrm{x})\right) \mathrm{S}\left\{\mathrm{mol} \mathrm{cm}^{-3} \mathrm{~s}^{-1}\right\} \\
& \mathrm{x}=\mathrm{P}_{\mathrm{O}_{2}} /\left(\mathrm{P}_{\mathrm{O}_{2}}+\left(\mathrm{K}_{\mathrm{T}} / \mathrm{K}_{\mathrm{B}}\right)\right), \mathrm{K}_{\mathrm{A}}=30.0 \cdot \exp (-15800 / \mathrm{T})\left\{\frac{\mathrm{g}}{\mathrm{cm}^{2} \mathrm{~s} \mathrm{~atm}}\right\}, \mathrm{K}_{\mathrm{B}}=8.0 \cdot 10^{-3} \cdot \exp (-7640 / \mathrm{T})\left\{\frac{\mathrm{g}}{\mathrm{cm}^{2} \mathrm{~s} \mathrm{~atm}}\right\}, \\
& \mathrm{K}_{\mathrm{T}}=1.51 \cdot 10^{5} \cdot \exp (-49800 / \mathrm{T})\left\{\frac{\mathrm{g}}{\mathrm{cm}^{2} \mathrm{~s}}\right\}, \mathrm{K}_{\mathrm{Z}}=27.0 \cdot \exp (3000 / \mathrm{T})\left\{\mathrm{atm}^{-1}\right\}
\end{aligned}
$$

Equation (5) gives the net-rate of surface oxidation at the more reactive A sites and the less reactive B sites. The fraction of $A$ sites is given by the term $x$ in Eq. (4) and the fraction of $B$ sites by (1-x). $\quad \mathrm{P}_{\mathrm{O}_{2}}$ (atm) is the partial pressure of oxygen in the CFD cell.

\section{e) Soot oxidation through $\mathrm{OH}$ radical:}

Soot oxidation via the $\mathrm{OH}$ radical was considered through the modified Fenimore and Jones [13] mechanism step.

$\mathrm{C}(\mathrm{s})+\mathrm{OH} \frac{\dot{\mathrm{R}}_{5}}{\mathrm{OO}}+\frac{1}{2} \mathrm{H}_{2}, \dot{\mathrm{R}}=1 \mathrm{IJ} \quad$ Of $\left\{\mathrm{mgl}_{\mathrm{H}} \mathrm{cm}^{-1 / 2} \mathrm{~s}\right\} \quad-3 \quad-1$

In the above expression, $\mathrm{X}_{\mathrm{OH}}$ is the $\mathrm{OH}$ mole fraction and $\gamma_{\mathrm{OH}}$ is the $\mathrm{OH}$ collision efficiency $(0.13$ in this study).

\section{f) PAH assisted surface growth /PAH coagulation}

Di Domenico et al. [14] used an approach for considering PAH-assisted growth on soot, originally developed by Frenklach and Wang [10] for PAH-PAH collision (dimerization or coagulation) leading to soot inception.

Cs+PAHk,j R6 Cs+k+j2H2, R6= $\gamma \mathrm{ks} \cdot \beta \mathrm{ks} \cdot \mathrm{PAHk}, \mathrm{j} \cdot \mathrm{N}$

where, $\mathrm{PAH}_{\mathrm{k}, \mathrm{j}}$ is a $\mathrm{PAH}$ species with $\mathrm{k}$ carbon and $\mathrm{j}$ hydrogen atoms. $\gamma_{\mathrm{ks}}$ is the PAH-soot collision efficiency ( 0.3 in this study) and $\beta_{\mathrm{ks}}$ is the frequency of PAH-soot collisions, the expression for which is, 
$\beta_{\mathrm{ks}}=2.2 \cdot \sqrt{\frac{\pi \cdot \mathrm{K}_{\mathrm{bc}} \cdot \mathrm{T}}{2 \mu \mathrm{i}, \mathrm{j}}} \cdot\left(\mathrm{d}_{\mathrm{p}}+\mathrm{d}_{\mathrm{PAH}}\right)^{2}\left\{\mathrm{~cm}^{3} \mathrm{~s}^{-1}\right\}$

where $d_{P A H}$ is the PAH collision diameter and $\mu_{i, j}$ is the reduced mass. Frenklach and Wang [10] used the PAH collision diameter,

$\mathrm{d}_{\mathrm{PAH}}=\mathrm{d}_{\mathrm{A}} \cdot \sqrt{\frac{2 \mathrm{~m}_{\mathrm{i}}}{3}}$

where $d_{A}$ is the size of a single aromatic ring the value for which is $1.395 \cdot 10^{-8} \cdot \sqrt{3}\{\mathrm{~cm}\}$ and $\mathrm{m}_{\mathrm{i}}$ is the mass of aromatic ring class, expressed in terms of number of carbon atoms in the aromatic. $\mu_{\mathrm{i}, \mathrm{j}}$ is the reduced mass and in this case, it is taken as the mass of the colliding gaseous PAH species. As the original model was used with the method of moments, the above implementation is simplified as a representative rate process for soot surface growth through aromatics. In the present study only $A_{1}$ (generally the highest concentration species among the aromatics and $\mathrm{PAH}$ ), resulting through the $\mathrm{C}_{3} / \mathrm{C}_{4}$ pathway, was considered for the growth process. However, it was found that it did not have a pronounced effect on the net soot mass.

\section{g) Transport equations for soot species and number densities:}

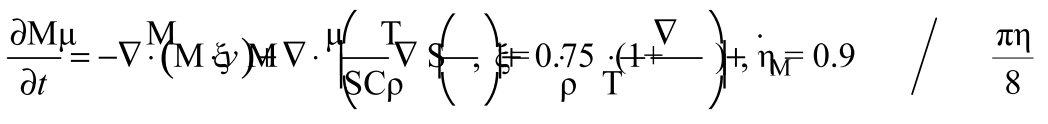

The above equation represents two additional transport equations that were solved in the CFD code. M stands for either soot species density, $\rho \mathrm{Y}_{\mathrm{c}(\mathrm{s})}$, in $\mathrm{g} \mathrm{cm}^{-3}$ or soot number density, $\mathrm{N}$, in particles $\mathrm{cm}^{-3}$, $v(\mathrm{~cm} / \mathrm{s})$ is the CFD gas-phase velocity, $\mathrm{SC}$ is the Schmidt number, $\mu$ is the computational cell viscosity,

$\mathrm{T}(\mathrm{K})$ is the cell temperature, and $\dot{\mathrm{S}}_{\mathrm{M}}$ represents source terms. The second term inside the bracket on the right hand side of Eq. (10) is the thermophoretic diffusion term which was modeled as a source term in KIVA. The accommodation factor $\eta=0.9$. The source terms for the respective equations are,

S $\rho$ YCs=16R1+2R2+6R6-R4-R5·MCsgcm3s, SN= 16R1·MCsMnuci- R3 particlescm3s, 
$\mathrm{M}_{\text {nuci }}$ is the mass of the soot inception particle nucleus, assumed to be of diameter $d_{\text {nuci }}=1.28 \mathrm{~nm}$ (approximately equivalent to 100 carbon atoms). More specific details of the model can be found in Vishwanathan and Reitz [8] and in Vishwanathan [11].

Recently, numerous studies have used this soot model with different PAH chemistry mechanisms for a variety of fuels for diesel combustion (Sukumaran et al. [15]), n-heptane/toluene combustion (Reitz et al. [16]), oxygenated fuel n-heptane-n-butanol combustion (Wang et al. [17]), and dual-fuel gasoline-diesel combustion (Yang et al. [18]). However, most of these studies focused on PAH chemistry improvements for different fuels and soot mass predictions. The current study focuses on soot number density and soot diameter predictions along with soot mass predictions. The model predicted soot mass was compared with various experimental results, and the associated discrepancies have been documented in detail elsewhere [8]. Also, Part-II of the present paper details some of the model prediction discrepancies using sensitivity analysis. In addition, the chemistry mechanisms were tested for predicting 1) Ignition delay times and compared with experimental shock-tube ignition delay data 2) PAH profiles in 0-D perfectly stirred reactors and in the Two-Stage Lagrangian (TSL) model framework against detailed chemistry mechanisms, and finally, 3) n-heptane lift-off lengths were compared against SANDIA constant volume experimental spray data. All this information was well documented in Ref. [8] and has been omitted here to avoid redundancy.

\section{Results and discussion}

\subsection{Spray chamber results}

Comparisons were made with Sandia constant volume spray chamber experimental data using a single-hole nozzle (http://www.ca.Sandia.gov/ecn/cvdata/frameset.html). Lift-off lengths, total soot mass, and 2-D soot distributions were compared. The lift-off length was defined as the distance from the tip of the injector to the axial location where significant $\mathrm{OH}$ radical formation was seen, consistent with Vishwanathan and Reitz [8]. The experimental lift-off lengths were obtained by $\mathrm{OH}$ chemiluminescence in the experiments of Pickett and Idicheria [19]. The lift-off length was averaged during the quasi-steady period of combustion 
for all cases, i.e., from $3.5 \mathrm{~ms}$ to $6.5 \mathrm{~ms}$ after start of injection (SOI), and the injection duration was $6.8 \mathrm{~ms}$. Predictions of time-averaged soot mass over the quasi-steady combustion period were also compared to the time-averaged experimental soot mass (estimated from soot extinction and laser induced incandescence (LII)), as shown in Figure 2 for the conditions in Table 1. With the Mech-1 chemistry mechanism, it is seen that at lower density $\left(\rho=14.8 \mathrm{~kg} / \mathrm{m}^{3}\right)$, the model does a very good job of predicting the total soot mass in the jet. For higher density $\left(\rho=30.0 \mathrm{~kg} / \mathrm{m}^{3}\right)$, and hence for higher in-cylinder pressures, the model captures the effect of pressure dependence on soot formation by predicting higher soot formation, however the total soot mass at moderate $\mathrm{O}_{2}$ concentration conditions is somewhat under-predicted and over-predicted at low $\mathrm{O}_{2}$ conditions. Mech-2 consistently predicts more soot than Mech-1 for all the conditions. Also, the predictions of soot mass using Mech-2 are closer to the experiments than Mech-1 for the high density conditions. Mech1 and Mech-2 chemistry mechanisms are fundamentally different and were reduced and tuned for replicating n-heptane and diesel combustion, respectively. The low temperature reaction rates involving ketohydroperoxyl radical, $\mathrm{C}_{2} \mathrm{H}_{4}$ and $\mathrm{C}_{2} \mathrm{H}_{2}$ chemistry are different between the two mechanisms. Particularly, Mech-2 reaction rates were tuned to mimic diesel soot formation and Mech-1 rates were tuned for n-heptane soot formation, and thus, soot formation increased with the Mech-2 chemistry mechanism, where the predominant contribution is from $\mathrm{C}_{2}$ reactions. Since $\mathrm{C}_{2} \mathrm{H}_{2}$ contributes to soot surface growth and predominant soot mass, variation in reaction rates of these reactions can cause different soot mass predictions by different mechanisms. Part-II of the paper gives a detailed sensitivity analysis of the reactions and their effect on soot mass predictions

It is also interesting to note that both the capture the so-called 'soot-bump', i.e., the soot peak at intermediate $\mathrm{O}_{2}$ concentrations. This peak occurs due to the competition between increased residence time (longer lift-off length) due to lower oxygen entrainment rates, and lower local temperatures for soot formation and oxidation, with lower $\mathrm{O}_{2}$ concentrations. Also, it is seen from Figure 2 that in terms of the present model implementation, the contribution of PAH induced surface growth is very much less, as seen by the inverted triangles at the $21 \% \mathrm{O}_{2}$ high temperature combustion and at the $8 \% \mathrm{O}_{2}$ LTC condition. Although not noticeable from the figure, the total soot mass as predicted by the model without PAH surface growth for the $21 \% \mathrm{O}_{2}$ condition was about $12 \mu \mathrm{g}$ while it was about $14 \mu \mathrm{g}$ considering PAH surface growth. However, for the LTC condition, the difference is insignificant. As previously mentioned, this sub-model 
may have a greater contribution when fuel aromatics are included in a fuel surrogate. All the results presented here consider the PAH induced surface growth sub-model.

Figures 3(a), 3(b) and 3(c) show the steady-state (6.5 ms after SOI) soot particle diameter, $d_{p} v s$. number of particles and $d_{p}$ vs. percent soot mass for $21 \% \mathrm{O}_{2}-\rho=14.8 \mathrm{~kg} / \mathrm{m}^{3}, 10 \% \mathrm{O}_{2}-\rho=14.8 \mathrm{~kg} / \mathrm{m}^{3}$, and $10 \% \mathrm{O}_{2}-\rho=30 \mathrm{~kg} / \mathrm{m}^{3}$, respectively. The $\mathrm{d}_{\mathrm{p}}$ vs. particle number histograms were obtained by grouping all the computational cells with soot diameters in bins. Finally, the total number of particles for each bin was obtained by summing over the number of particles in all the cells belonging to the corresponding bin (i.e., cells within the $d_{p}$ range). For each cell, the number of particles was obtained from the product of the cell soot number density and the cell volume. The contribution of each bin to the percent soot mass was also obtained similarly. The model predicts that most of the particles, in terms of both mass and number, are around $10-20 \mathrm{~nm}$ for the $21 \% \mathrm{O}_{2}, \rho=14.8 \mathrm{~kg} / \mathrm{m}^{3}$ condition. For the $10 \% \mathrm{O}_{2}, \rho=14.8 \mathrm{~kg} / \mathrm{m}^{3}$ case (higher simulated EGR), it is seen that most of the particles under steady state are between 20 and $30 \mathrm{~nm}$. Finally, for the $10 \% \mathrm{O}_{2}, \rho=30 \mathrm{~kg} / \mathrm{m}^{3}$ high sooting condition the sizeable contribution to the mass and particle number is from particles with sizes $20-40 \mathrm{~nm}$ with some contribution also from the $40-50 \mathrm{~nm}$ size range. In general, it is seen that when the ambient oxygen is reduced (from $21 \% \mathrm{O}_{2}$ to $10 \% \mathrm{O}_{2}$ ) at the same in-cylinder density, or when the in-cylinder density is increased at the same in-cylinder ambient oxygen level (from 14.8 $\mathrm{kg} / \mathrm{m}^{3}$ to $30 \mathrm{~kg} / \mathrm{m}^{3}$ ) the particle size increases.

Table 2 shows the constant volume combustion chamber experimental conditions for diesel fuel combustion with different injection pressures and nozzle diameters obtained from the Sandia database (http://www.sandia.gov/ecn/cvdata/dsearch/frameset.php). The simulations were performed with the Mech-2 + PAH-1 chemistry mechanism with tetradecane assumed for the fuel physical properties. Figure 4 and Figure 5 show the steady-state soot volume fraction distributions at four different injection pressures and with four different nozzle diameters, respectively, with the dashed lines representing the lift-off lengths. As can be seen, the model is able to predict higher net soot at lower injection pressures and with larger nozzle diameters, in agreement with the experimental trends.

In general, the peak values of the model predicted volume fraction are modestly under-predicted as compared to the experiments, except for the no-sooting $50 \mu$ diameter case. In general, the model predicted width of the soot zones is smaller than the experimental soot zones. This discrepancy may be due to the 
radially-narrower rich cores predicted by the model when compared to the experiments, or due to enhanced soot oxidation by the peripheral $\mathrm{OH}$ in the flame zone, or both. For the $50 \mu$ diameter case, even though the model shows a soot amount peak of $2 \mathrm{ppm}$, the total amount of soot per unit injected mass is very low, as seen in Figure 6. Figure 6 also shows that the effect of nozzle diameter is more prominent in soot reduction due to enhanced air entrainment as compared to increasing the fuel injection pressure. Figure 6 also shows that with increasing nozzle size, the soot core increases due to the wider rich zones caused by relatively poorer entrainment.

Figures 7(a) and 7(b) show the $d_{p}$ vs. soot mass histograms as a function of injection pressure and nozzle diameter, respectively, with $1 \mathrm{~nm}$ bins just before the end of injection ( $\sim 6.8 \mathrm{~ms}$ after SOI). For relatively low-sooting conditions either with higher injection pressures or smaller nozzle-hole diameters, there is a relatively narrow normal distribution of the soot size with respect to the soot mass contribution and there is a distinct diameter with maximum soot mass contribution. For lower injection pressures and larger nozzle holes, the contribution from the predominant diameter is reduced and the distribution is wider. In general, the soot size predictions are unimodal and are also higher for high-sooting conditions as compared to low-sooting conditions due to higher soot inception and surface-growth rates in the soot core region.

\subsection{Optical engine results}

The performance of the soot model was also evaluated for in-cylinder soot formation and oxidation in the Sandia Cummins N-14 series optical engine with \#2 diesel fuel. Four different engine combustion conditions, two high temperature conditions (premixed combustion and conventional diesel diffusion combustion high temperature conditions (HTC)) and two LTC conditions (early injection LTC and late injection LTC) were studied by Singh et al. [20]. The boundary conditions for the numerical simulations are shown in Table 3. Figure 8 shows the in-cylinder pressure and heat release rate (HRR) predicted by the Mech-2 + PAH-1 mechanism as compared to the experiments for all four conditions. It is seen that, in general, the model is able to predict the in-cylinder pressure and heat release history well for the different combustion regimes. The model predicted HRR is the chemical heat release (exclusive of wall heat transfer) and hence is expected to be somewhat higher than the experimental HRR. 
Singh et al. [20] used the two-color technique to monitor the in-cylinder soot evolution in the experiments. Two laser wavelengths were used to obtain the soot path length $\left(f_{v} L\right)$ and temperature, and the flame area $\left(\mathrm{A}_{\text {flame }}\right)$ could be inferred from the images only in the piston-bowl region, finally yielding an expression for soot mass as:

Soot mass $\{\mathrm{g} / \mathrm{kg}-\mathrm{f}\}=\frac{\left(\mathrm{f}_{\mathrm{v}} \mathrm{L}\right) \mathrm{p}\left(\mathrm{A}_{\text {flame }}\right) \cdot{ }_{\mathrm{C}(\mathrm{s})}}{\text { Injected fuel mass }}$

The model predicted soot volume fraction $\left(f_{v}\right)$ and cell temperatures were used to infer the intensity of radiation, using the two-color equations (Singh et al. [21]). Finally, $\mathrm{A}_{\text {flame }}$ was obtained using the projected computational cell area in the piston bowl with intensity greater than a $15 \%$ threshold, as used in the experiments and the soot mass calculated using Equation (12) was compared to the experimental soot mass.

Figure 9 shows the in-cylinder soot history for the four combustion cases. The model is seen to predict the soot formation and oxidation for all the cases quantitatively, except the premixed HTC case. Also, for the HTC diffusion case, a second bump is seen in the experiments that is not predicted by the model. This could be caused by faster soot oxidation predicted by the model. Another reason could be the uncertainty in soot mass obtained by the two-color method, as the two-color procedure is a line-of-sight technique, where the detector signals are biased towards the hottest soot in the combustion chamber [8]. However, the model was able to predict lower soot in going from HTC-diffusion to HTC-premixed combustion, as expected. The model also predicted the large decrease in soot from HTC to LTC, as seen by comparing the peak soot values. Some of the discrepancies may be due to the lack of fuel-aromatic pathways to soot contributions, particularly at LTC conditions. According to Heywood [22], the mechanism of soot formation at higher temperatures $(>1900 \mathrm{~K})$ may be dominated by linear unsaturated hydrocarbons like $\mathrm{C}_{2} \mathrm{H}_{2}$ due to the faster fuel decomposition, while PAHs contribute to the soot at lower flame temperatures, where the LTC regime of operation falls.

For the two conditions, HTC diffusion and LTC early injection condition, where the soot model predictions are closer to the experiments, two-sets of $\Phi$-T maps were generated. The first map (Figure 10) relates cells with maximum $\Phi$, maximum temperature, maximum soot, and maximum NO at different crank angles (transient $\Phi$-T map) while the second map (Figure 11) shows, at the maximum sooting crank angle (4 
ATDC for diffusion combustion and -4 ATDC for early injection), computational cells with more than 50\% of either the maximum NO value or maximum soot value at that crank angle position (The NO and soot peninsulas in the maps are from Akihama et al. [1]).

As seen from Figure 10, there is a good correlation between the maximum temperature cells (rectangles) and maximum NO cells (inverted triangles), while the maximum $\Phi$ cells (solid circles) correlate well with the maximum soot cells (open circles) above $1750 \mathrm{~K}$ at the different crank angles. As seen in Figure 11, the operating regime clearly shifts from high soot and high NOx locations (rectangles) to low soot and low NOx locations (circles), making this strategy attractive for medium loads. Thus, the soot model predictions seem to qualitatively agree well with conventional understanding.

Figure 12 shows the evolution of $d_{p}$ vs. particle number and $d_{p}$ vs. percent soot mass for the HTC diffusion case at different crank angles. As seen in Figure 12(a), soot particles only up to $30 \mathrm{~nm}$ are formed initially and most of the mass is accumulated within 10-30 nm soot particles. At 5 CAD ATDC (Figure 12(b)), most of the soot mass is accumulated in the 20-60 $\mathrm{nm}$ range with maximum number of particles and mass in the 30-40 nm range. At a later crank angle, CA $=10$ ATDC (Figure 12(c)), the soot mass is quite evenly distributed between 30 to $120 \mathrm{~nm}$ particles. The larger size soot particle population is due to enhanced surface growth and soot coagulation. Finally, in the soot oxidative phase at 20 CAD ATDC (Figure 12(d)), higher particle size soot is oxidized and the soot population is seen to vary from 20 to $50 \mathrm{~nm}$ that contributes significant mass. This is also seen from in-cylinder contours of soot species density $\left(\mathrm{g} / \mathrm{cm}^{3}\right)$, OH species density $\left(\mathrm{g} / \mathrm{cm}^{3}\right)$ and $\mathrm{d}_{\mathrm{p}}(\mathrm{nm})$ for 10,15 , and 20 CAD ATDC as shown in Figure 13, which is a cut-plane view along the spray axis. It is seen that at $10 \mathrm{CAD}$, the soot concentration is very high, which is progressively oxidized by the presence of $\mathrm{OH}$ radicals and hence the residual soot mass that is left behind at $20 \mathrm{CAD}$ is of smaller size.

Figure 14 shows the evolution of $d_{p}$ vs. number density and $d_{p}$ vs. percent soot mass for the LTC early injection case at different crank angles. As seen in the figure, this combustion condition is dominated by in-cylinder soot diameters that do not exceed $50 \mathrm{~nm}$. Initially, predominant particles are in the size range between 10 and $30 \mathrm{~nm}$ (-5 CAD ATDC), but at later crank angles higher diameter particles are also populated $(\mathrm{CAD} A T D C=0$ and $\mathrm{CAD}$ ATDC $=5)$. At a crank angle of $20 \mathrm{ATDC}$, particles ranging from 0 to $50 \mathrm{~nm}$ are populated fairly equally in terms of their mass, but the number of larger particles progressively decreases. 
Thus, under the present conditions of study, the HTC-diffusion condition is characterized by high soot, higher in-cylinder particle numbers and larger in-cylinder particles, at least for a short period of time, that eventually oxidize, while the LTC early injection regime is characterized by significantly lower soot, lower in-cylinder particle number and particle diameters that are not widely populated even for a short period

of time. These results explored the in-cylinder evolution of soot. The following section explores the evolution of particles closer to EVO.

\subsection{Metal engine-out soot predictions}

In this section model predicted results are compared with experimental data obtained from a lightduty GM 1.9L single cylinder version engine operated under PCCI conditions. The EVO model predictions are compared with experimental AVL filter smoke number (FSN) converted values using:

$\mathrm{C}\left\{\mathrm{mg} / \mathrm{m}^{3}\right\}=\frac{1}{0.405} \cdot 4.95 \cdot \mathrm{FSN} \cdot \exp (0.38 \cdot \mathrm{FSN})$

where $\mathrm{C}$ is the soot mass per sample exhaust volume. The above correlation was primarily developed for conventional diesel combustion although recent work by Northrop et al. [23] has found that it can also be used for partially premixed LTC and biodiesel combustion without any need for modifications. The model performance was tested at an EGR rate of $52 \%$, and a main injection sweep was done from -8 to -2 CAD ATDC. The first pulse injection pressure (300 bar) at -51 CAD ATDC was significantly less than the second injection pressure (1200 bar) to reduce spray-wall impingement (Swor [24]). Table 4 summarizes the tested conditions and Figures 15(a) and 15 (b) show the model predicted pressure and heat release traces as compared to the experiments for main SOI of -8 CAD ATDC and -2 ATDC. For the SOI $=-2$ CAD ATDC case (Figure 15(b)), there were significant variations in the in-cylinder pressures for different experimental runs and thus three traces are shown. Figure 15(c) shows the model predicted exhaust soot compared to the average of three engine measurements with the associated error bars and Figure 15(d) shows the in-cylinder soot formation and oxidation histories.

Figures 16 (a), (b) and (c) show particle number vs. $d_{p}$ and particle number vs. soot mass for the SOI $=-8 \mathrm{CAD}$ ATDC case at different crank angles and Figure 16(d) shows for the SOI $=-2$ CAD ATDC case at EVO. It is seen that the soot diameter corresponding to the maximum soot mass transitions from $20-30 \mathrm{~nm}$ 
size particles (Figure 16(a)) to $40-50 \mathrm{~nm}$ size particles (Figure 16(b)) at $40 \mathrm{CAD}$. At the time of EVO (Figure 15(c)), most of the particle mass is between 30 to $35 \mathrm{~nm}$ and 50 to $65 \mathrm{~nm}$ size particles, while a higher number of particles is seen between 15 to $35 \mathrm{~nm}$. Interestingly, two characteristic modes are seen in this case. Figure 16(d) shows the EVO distribution (112 CAD ATDC) for SOI $=-2$ CAD ATDC in $1 \mathrm{~nm}$ bins. In this case, it is seen that higher soot size particles are unpopulated and all the mass is found in particles with size less than $40 \mathrm{~nm}$. The SOI $=-8$ CAD ATDC case is characterized by higher soot formation as compared to the SOI $=-2$ CAD ATDC, as seen from Figure 15(d). The higher soot formation rate due to higher inception and surface growth rates coupled with slower oxidation rates after 40 CAD ATDC, lead to the larger particle size population as compared to the SOI $=-2$ CAD ATDC case at EVO.

These results demonstrate that the present soot model can be effectively used for relative comparisons of exhaust soot diameter and particle number distributions involving different parametric sweeps. This capability is very important for analysis-led engine design and combustion strategy development for future diesel engines.

\section{Summary and conclusions}

In the current study a previously developed soot model was applied to study a variety of combustion regimes, including conventional diesel combustion, high-EGR LTC, and multiple injection PCCI conditions. The following conclusions were drawn regarding the soot mass predictions:

- For the constant volume chamber combustion simulations, the model was able to reproduce the trend of high soot at lower injection pressures or when larger nozzle diameter holes are used. The effect of decreasing the nozzle hole diameter to about $50 \mu$ is more pronounced than increasing the injection/rail pressure to $190 \mathrm{MPa}$ for reducing soot formation due to the enhanced entrainment. The in-cylinder soot peaks were modestly under-predicted by the model except for the $50 \mu$ nozzle hole diameter case. The widths of the sooting zones were smaller than seen in the experimental sprays, which is possibly due to narrower rich spray cores predicted by the model compared to the experiments, or to enhanced modelpredicted soot oxidation.

- For the Sandia optical engine study, the model yielded higher in-cylinder soot formation for high temperature diffusion combustion compared to high temperature premixed combustion. The early and 
late injection LTC cases yielded much lower in-cylinder soot formation. The model predictions agreed very well to the experiments for diffusion combustion and early injection LTC.

- Finally, comparisons with engine-out soot data from a metal light-duty engine were made. The model did not need any additional tuning of the calibration constants and the model predicted soot at EVO compared well with PCCI experiments over a sweep of main SOI timings.

In terms of predictions of soot particle size, the following observations were made:

- Generally, the soot particle size predicted by the model was larger for high-sooting conditions compared to low-sooting conditions over the studied parametric sweeps (SOI, EGR etc.).

- For steady-state combustion in the spray chamber, the soot size at the maximum mass fraction location was seen to increase with either reducing in-cylinder $\mathrm{O}_{2}$ at the same in-cylinder density, or by increasing chamber density at the same in-cylinder $\mathrm{O}_{2}$ volume fraction. Also, the soot size contribution corresponding to maximum soot mass was seen to marginally decrease with decreasing nozzle diameter (21 $\mathrm{nm}$ for $180 \mu$ to $13 \mathrm{~nm}$ for $50 \mu$ ), or by increasing injection pressures ( $23 \mathrm{~nm}$ for $40 \mathrm{MPa}$ to $18 \mathrm{~nm}$ for $190 \mathrm{MPa}$ ). Similar trends for soot primary particle diameter with increasing diesel injection pressures $(\sim 18.5 \mathrm{~nm}$ at $50 \mathrm{MPa}, \sim 18 \mathrm{~nm}$ at $90 \mathrm{MPa}$, and $\sim 6 \mathrm{~nm}$ at $130 \mathrm{MPa})$ were seen by Ryser et al. [25] using time-resolved laser induced incandescence. In the engine study of Mathis et al. [26], at low load, transmission electron microscope (TEM) analysis yielded primary particle diameters of $32.5 \mathrm{~nm}, 29.6$ $\mathrm{nm}$ and $17.5 \mathrm{~nm}$ when operated at injection pressures of 50,110 and $140 \mathrm{MPa}$, respectively. However, at high load an increase in the rail pressure from $80 \mathrm{MPa}$ to $140 \mathrm{MPa}$ yielded only a small reduction from $21.4 \mathrm{~nm}$ to $20.4 \mathrm{~nm}$. Thus, the current model predictions agreed well with these experimental trends in soot diameter.

- For the metal engine with PCCI combustion, the soot particle size was seen to decrease with retarded main SOI (-8 CAD ATDC and -2 CAD ATDC) at EVO. This was due to higher soot formation, coupled with lower soot oxidation beyond $40 \mathrm{CAD}$ ATDC for the early injection case.

- In the current study a unimodal type soot size distribution with respect to soot particle number or soot mass was obtained for all simulations, except for the SOI $=-8$ CAD ATDC engine case. This may be a function of higher residence time (early injection) available for soot surface growth and coagulation, leading to larger particles and lower soot oxidation rates (inadequate oxidation of smaller size particles). 


\section{Acknowledgments}

The authors would like to thank the DOE Sandia and Oak Ridge National Laboratories for supporting this work.

\section{References}

1. Akihama, K., Takatori, Y., Inagaki, K., Sasaki, S., and Dean, A. M. (2001). Mechanism of the smokeless rich diesel combustion by reducing temperature, SAE Technical Paper 2001-01-0655.

2. Tree, D. R., and Svensson, K. I. (2007). Soot processes in compression ignition engines, Progress in Energy and Combustion Science, 33(3), 272-309.

3. Pickett, L. M., and Siebers, D. L. (2004). Soot in diesel fuel jets: Effects of ambient temperature, ambient density, and injection pressure, Combustion and Flame, 138(1-2), 114-35.

4. Johnson, T. V. (2010). Review of diesel emissions and control, SAE Technical Paper 2010-01-0301.

5. Kokjohn, S. L., Hanson, R. M., Splitter, D. A., and Reitz, R. D. (2010). Experiments and modeling of dual-fuel HCCI and PCCI combustion using in-cylinder fuel blending, SAE International Journal of Engines, 2(2), 24-39.

6. Kong, S. C., and Reitz, R. D. (2002). Application of detailed chemistry and CFD for predicting direct injection HCCI engine combustion and emissions, Proceedings of the Combustion Institute, 29(1), 663-69.

7. Ra, Y., and Reitz, R. D. (2008). A reduced chemical kinetic model for IC engine combustion simulations with primary reference fuels, Combustion and Flame, 155(4), 713-38.

8. Vishwanathan, G., \& Reitz, R. D. (2010). Development of a practical soot modeling approach and its application to low-temperature diesel combustion. Combustion Science and Technology, 182(8), $1050-82$

9. Xi, J., and Zhong, B. J. (2006). Reduced kinetic mechanism of n-heptane oxidation in modeling polycyclic aromatic hydrocarbon formation in diesel combustion, Chemical Engineering \& Technology, 29(12), 1461-68.

10. Frenklach, M., and Wang, H. (1994). Detailed mechanism and modeling of soot particle formation. In Soot formation in combustion: Mechanisms and models, 162-190, Springer-verlag, Berlin. 
11. Vishwanathan, G. (2011). Development and Application of a Practical Soot Modeling Approach for Low Temperature Diesel Combustion, Doctoral dissertation, University of Wisconsin--Madison.

12. Nagle, J., and Strickland-Constable, R. F. (1962). Oxidation of carbon between 1000-2000 C, Proceedings of the Fifth Carbon Conference, 1, 154-64.

13. Fenimore, C. P., and Jones, G. W. (1967). Oxidation of soot by hydroxyl radicals, The Journal of Physical Chemistry, 71(3), 593-97.

14. Di Domenico, M., Gerlinger, P., and Aigner, M. (2010). Development and validation of a new soot formation model for gas turbine combustor simulations, Combustion and Flame, 157(2), 246-58.

15. Sukumaran, S., Van Huynh, C., \& Kong, S. C. (2013). Numerical Modeling of Soot Emissions in Diesel Sprays Based on Detailed Fuel and PAH Chemistry. Combustion Science and Technology, 185(11), 1696-1714.

16. Wang, H., Jiao, Q., Yao, M., Yang, B., Qiu, L., \& Reitz, R. D. (2013). Development of an nheptane/toluene/polyaromatic hydrocarbon mechanism and its application for combustion and soot prediction. International Journal of Engine Research, 14(5), 434-51.

17. Wang, H., Reitz, R.D., Yao, M., Yang, B., Jiao, Q., \& Qiu, L. (2013). Development of an nheptane-n-butanol-PAH mechanism and its application for combustion and soot prediction. Combustion and Flame, 160(3), 504-19.

18. Yang, B., Yao, M., Cheng, W. K., Li, Y., Zheng, Z., \& Li, S. (2014). Experimental and numerical study on different dual-fuel combustion modes fuelled with gasoline and diesel. Applied Energy, $113,722-33$.

19. Pickett, L. M., and Idicheria, C. A. (2006). Effects of ambient temperature and density on soot formation under high-EGR conditions, THIESEL 2006: Conference on Thermo-and Fluid Dynamic Processes in Diesel Engines.

20. Singh, S., Reitz, R. D., Musculus, M. P. B., and Lachaux, T. (2007). Validation of engine combustion models against detailed in-cylinder optical diagnostics data for a heavy-duty compression-ignition engine, International Journal of Engine Research, 8(1), 97-126.

21. Singh, S., Reitz, R. D., and Musculus, M. P. B. (2005). 2-color thermometry experiments and highspeed imaging of multi-mode diesel engine combustion, SAE Transactions, 114(4), 1605-21. 
22. Heywood, J. B. (1988). Internal combustion engine fundamentals. McGraw-Hill, New York.

23. Northrop, W. F., Bohac, S. V., Assanis, D. N., and Chin, J. Y. (2010). Comparison of filter smoke number and elemental carbon mass from partially premixed low temperature combustion in a direct injection diesel engine, Proceedings of the ASME Internal Combustion Engine Division Fall Technical Conference.

24. Swor, T. (2009). Experimental investigation of adaptive injection strategies through low and high pressure split injections, MS Thesis, University of Wisconsin-Madison.

25. Ryser, R., Gerber, T., and Dreier, T. (2009). Soot particle sizing during high-pressure diesel spray combustion via time-resolved laser-induced incandescence, Combustion and Flame, 156(1), 120-9.

26. Mathis, U., Mohr, M., Kaegi, R., Bertola, A., and Boulouchos, K. (2005). Influence of diesel engine combustion parameters on primary soot particle diameter, Environmental Science and Technology, 39(6), 1887-92. 


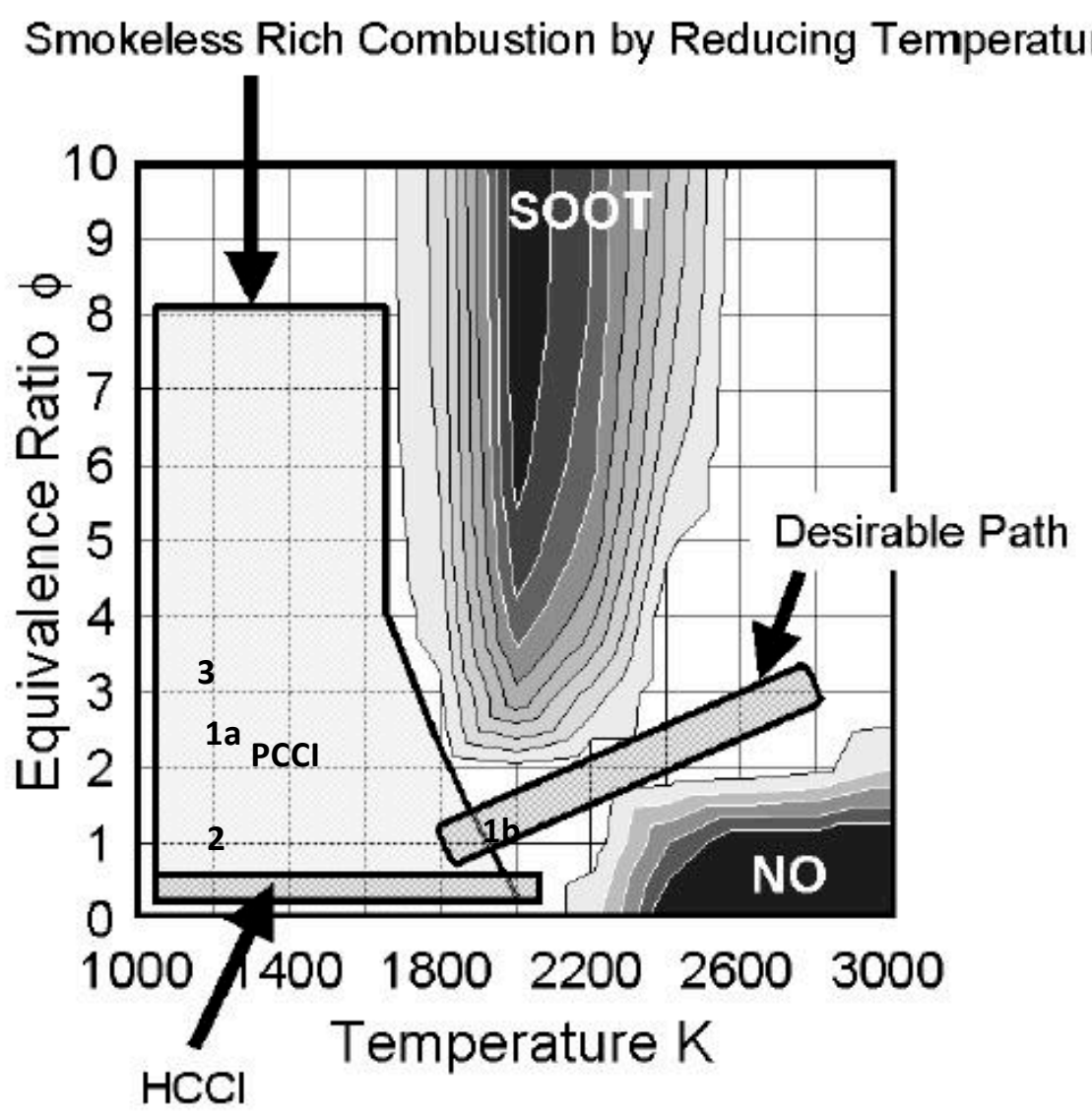

Figure 1: Generalized $\Phi-\mathrm{T}$ map showing HCCI, PCCI and LTC regimes of operation (Original figure from Akihama et al. [1] and modified based on Tree and Svensson [2]). 


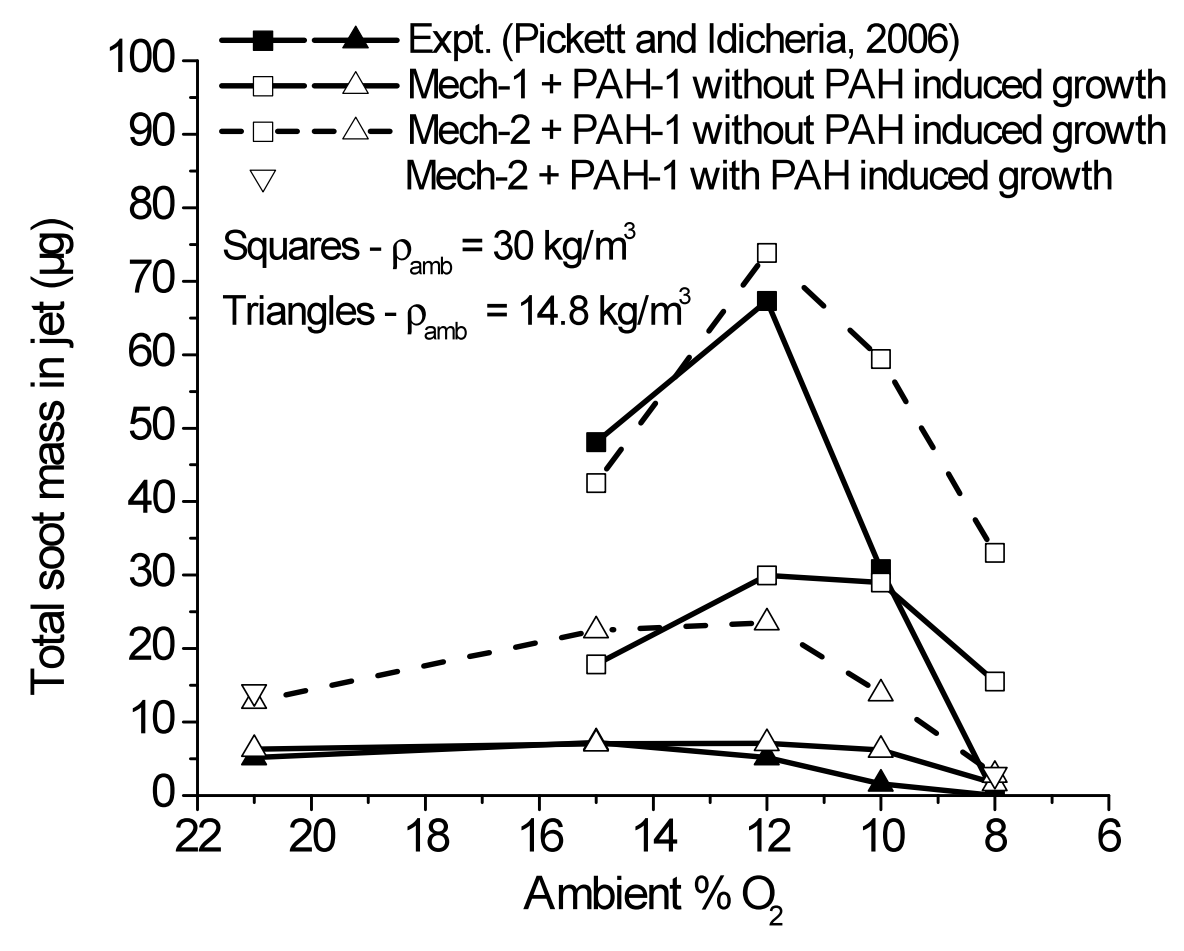

Figure 2: Model predicted total soot mass in the n-heptane jet as compared to the experiments [19]. 

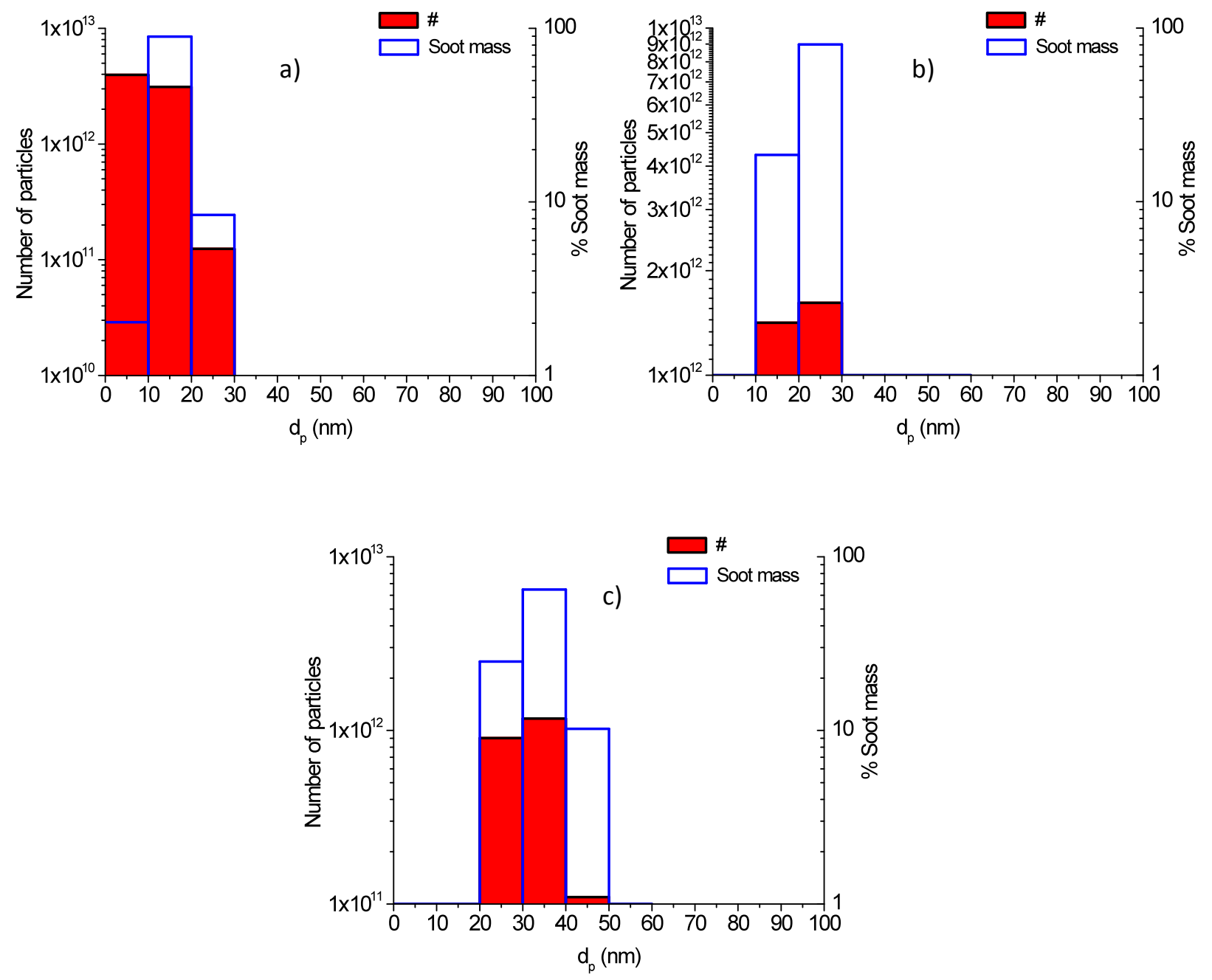

Figure 3: Histograms of $d_{p}$ vs. number of particles and $d_{p}$ vs. soot mass at $6.5 \mathrm{~ms}$ after SOI for a) $21 \% \mathrm{O}_{2}, \rho=14.8 \mathrm{~kg} / \mathrm{m}^{3}$, b) $10 \% \mathrm{O}_{2}, \rho=14.8 \mathrm{~kg} / \mathrm{m}^{3}$, and c) $10 \% \mathrm{O}_{2}, \rho=30 \mathrm{~kg} / \mathrm{m}^{3}$. The plots shows the effect of in-cylinder oxygen and density. 


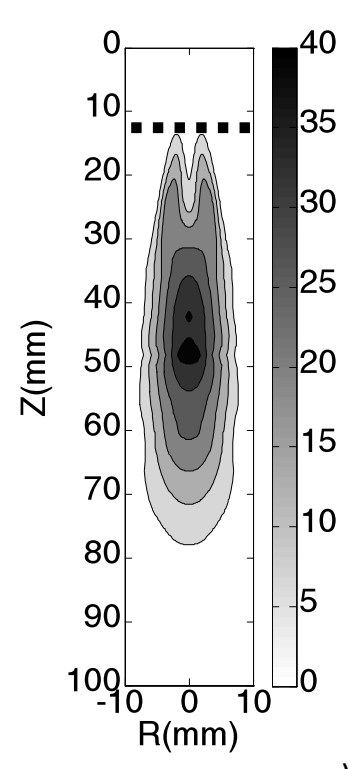

a)
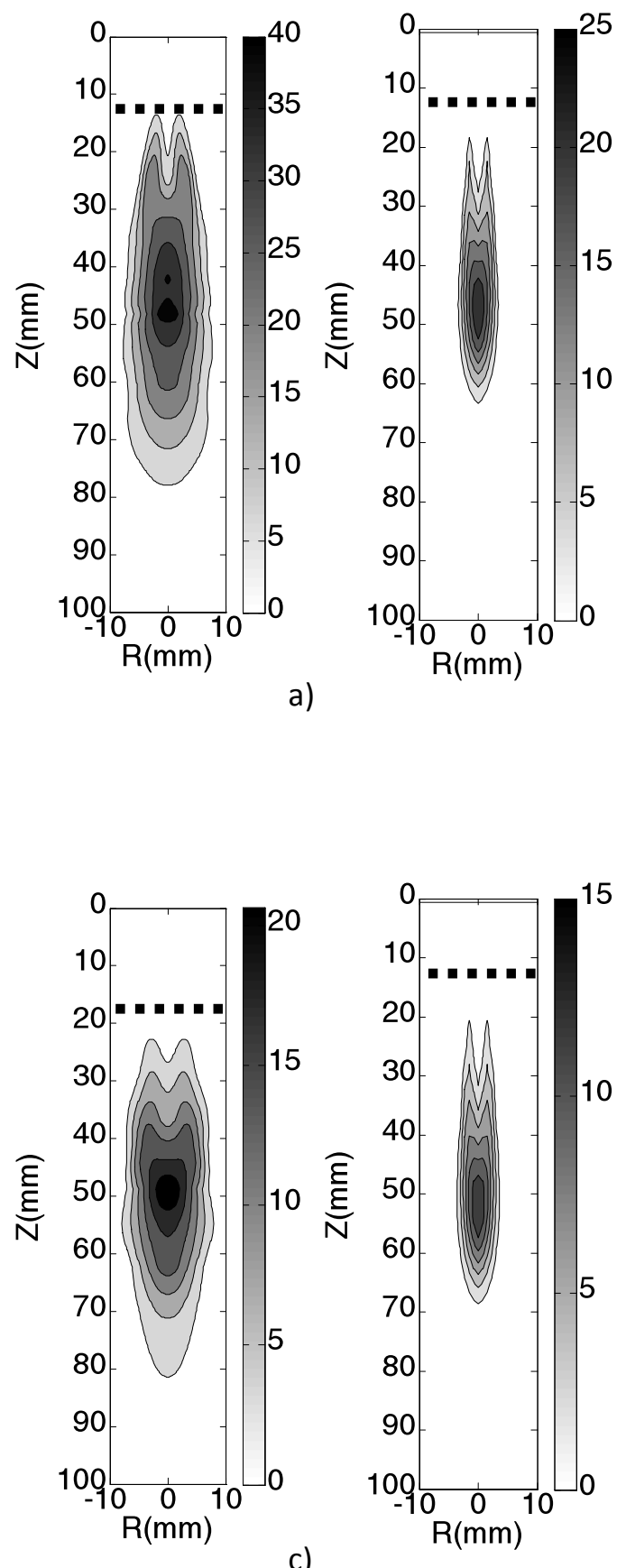

c)

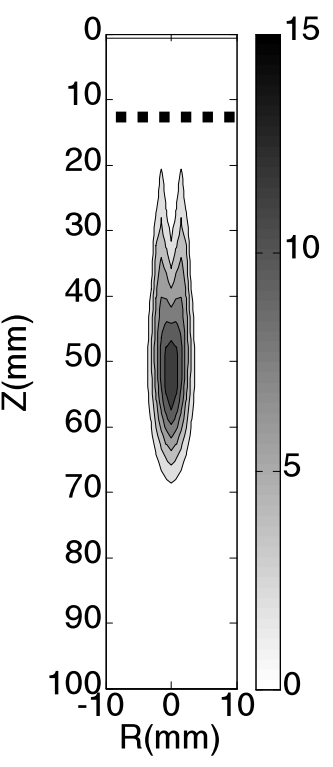

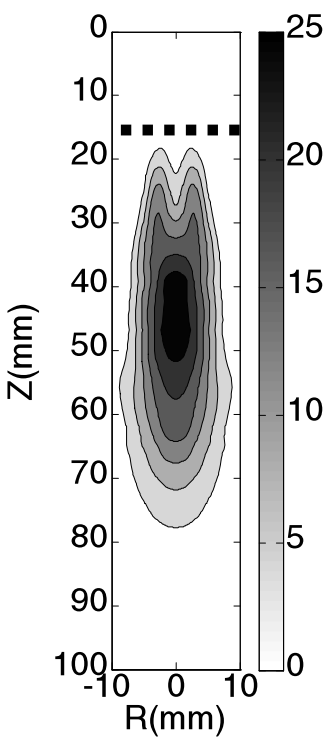

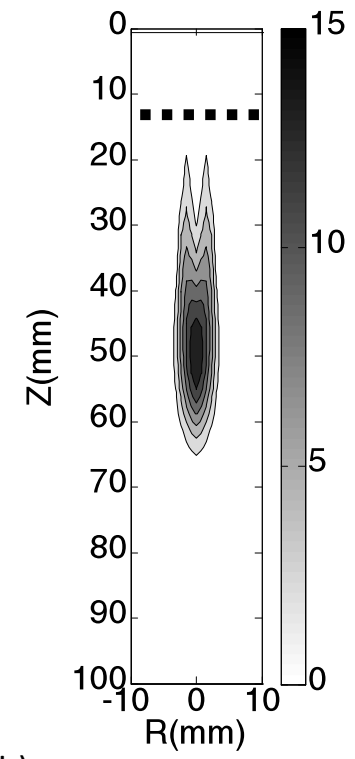

b)

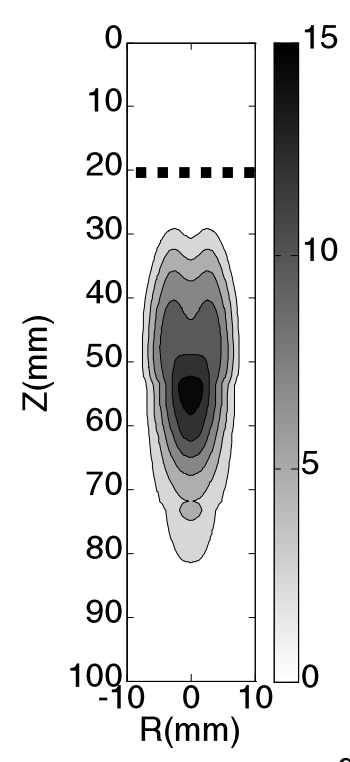

d)

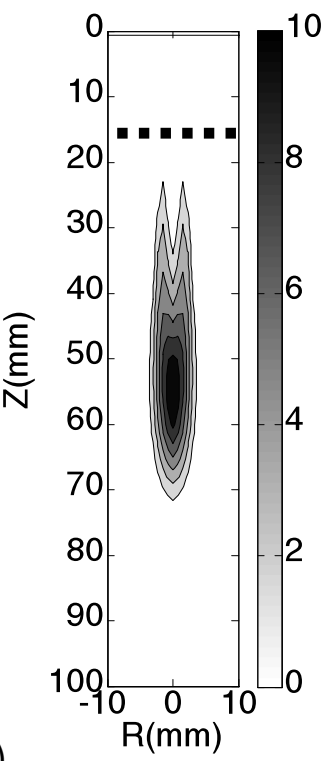

Figure 4: Comparison of model predicted soot volume fraction $(\mathrm{ppm})$ distributions (right) with experiments (left) using $100 \mu$ nozzle diameter at injection pressures of a) $40 \mathrm{MPa}$, b) $90 \mathrm{MPa}$, c) 140 MPa, and d) $190 \mathrm{MPa}$. Experimental results can be found in http://www.sandia.gov/ecn/cvdata/dsearch/frameset.php 

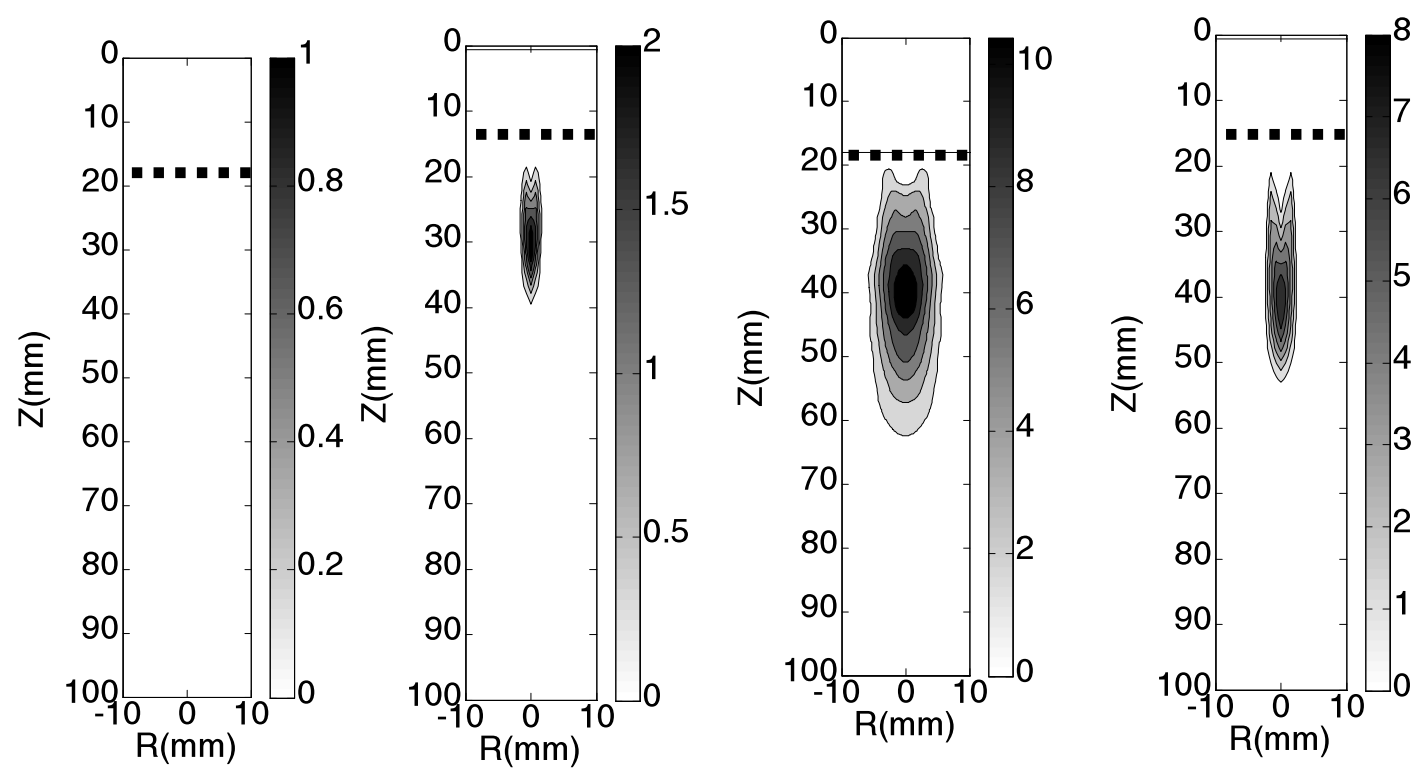

a)

b)
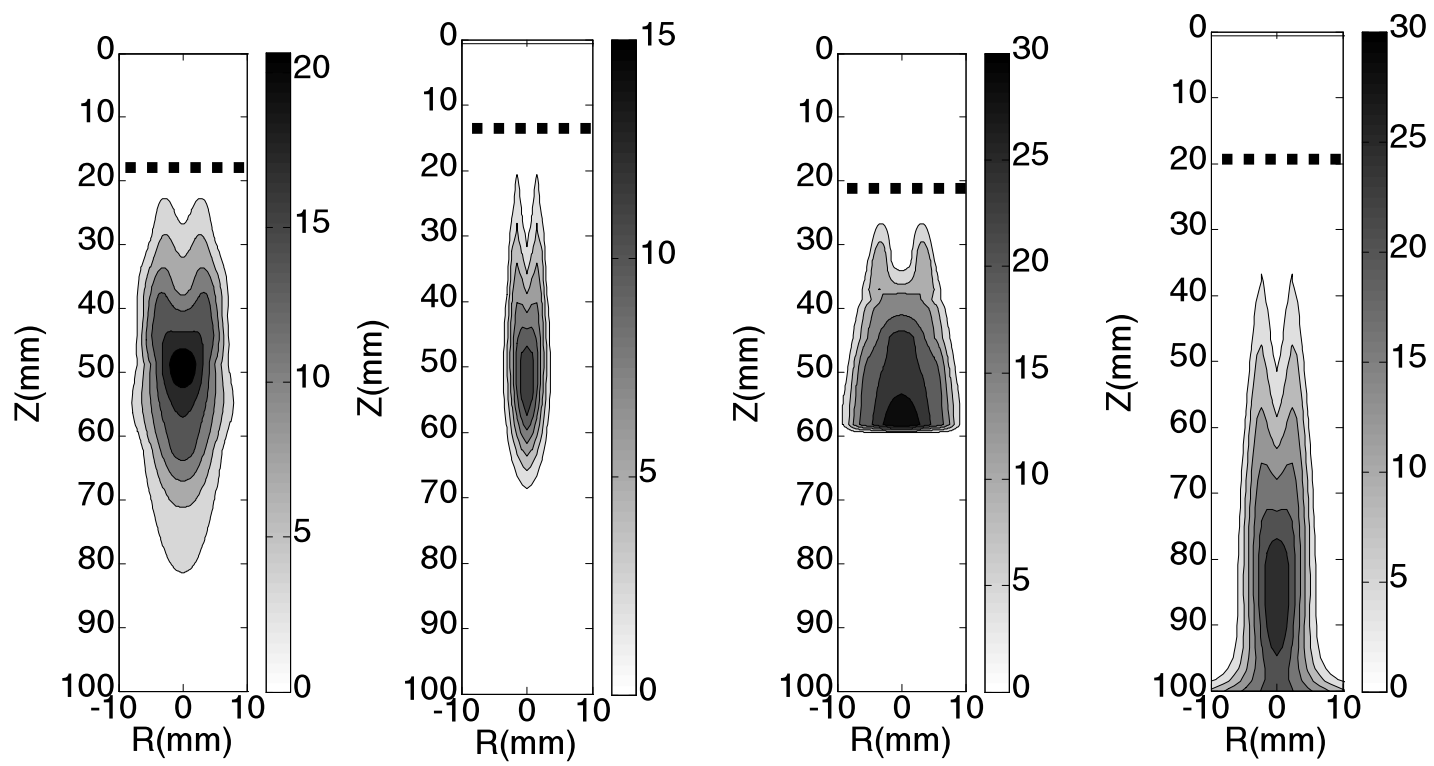

c)

d)

Figure 5: Comparison of model predicted soot volume fraction ( $\mathrm{ppm}$ ) distributions (right) with experiments (left) for $140 \mathrm{MPa}$ injection pressure with nozzle diameters of a) $50 \mu$, b) $71 \mu$, c) $100 \mu$, and d) $180 \mu$. Experimental results can be found in http://www.sandia.gov/ecn/cvdata/dsearch/frameset.php 


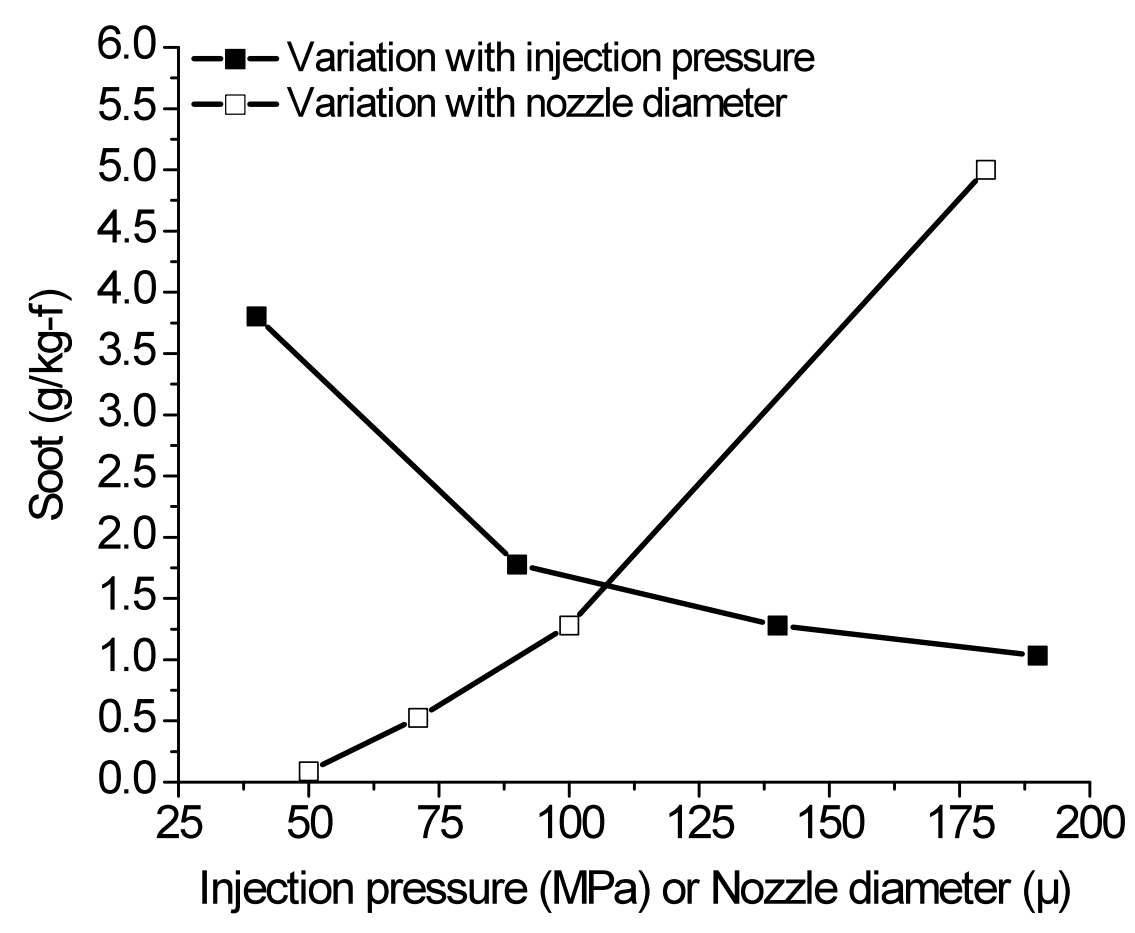

Figure 6: Variation of model predicted steady-state total in-cylinder soot mass (per unit injected fuel mass) with injection pressure and nozzle diameter. 

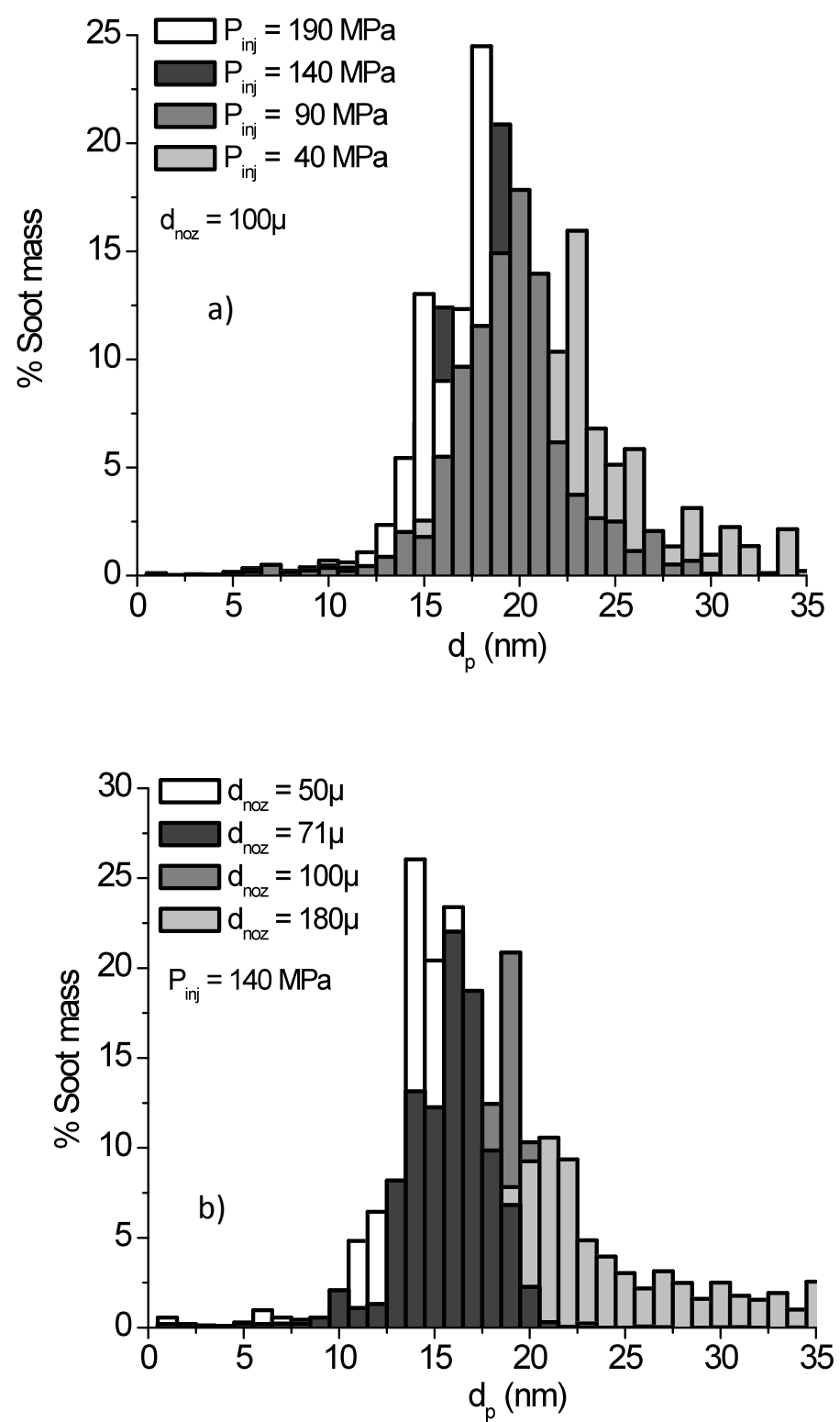

Figure 7: Variation of $d_{p}$ vs. soot mass histograms at a) different injection pressures and b) different nozzle diameters 

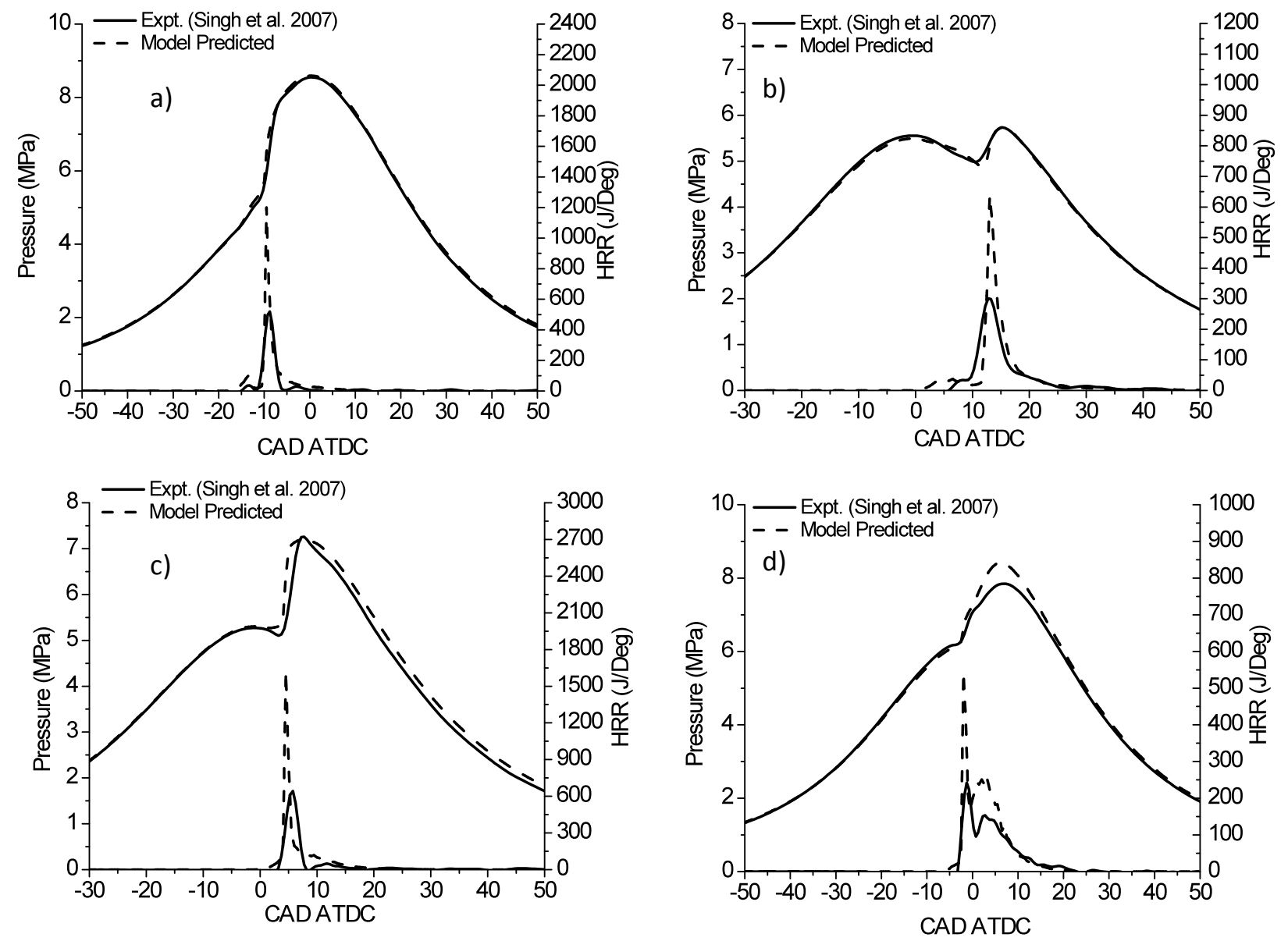

Figure 8: Model predicted pressure and heat release traces as compared to the experiments for a) high temperature premixed combustion b) late injection low temperature combustion c) early injection low temperature combustion and d) high temperature diffusion combustion. 


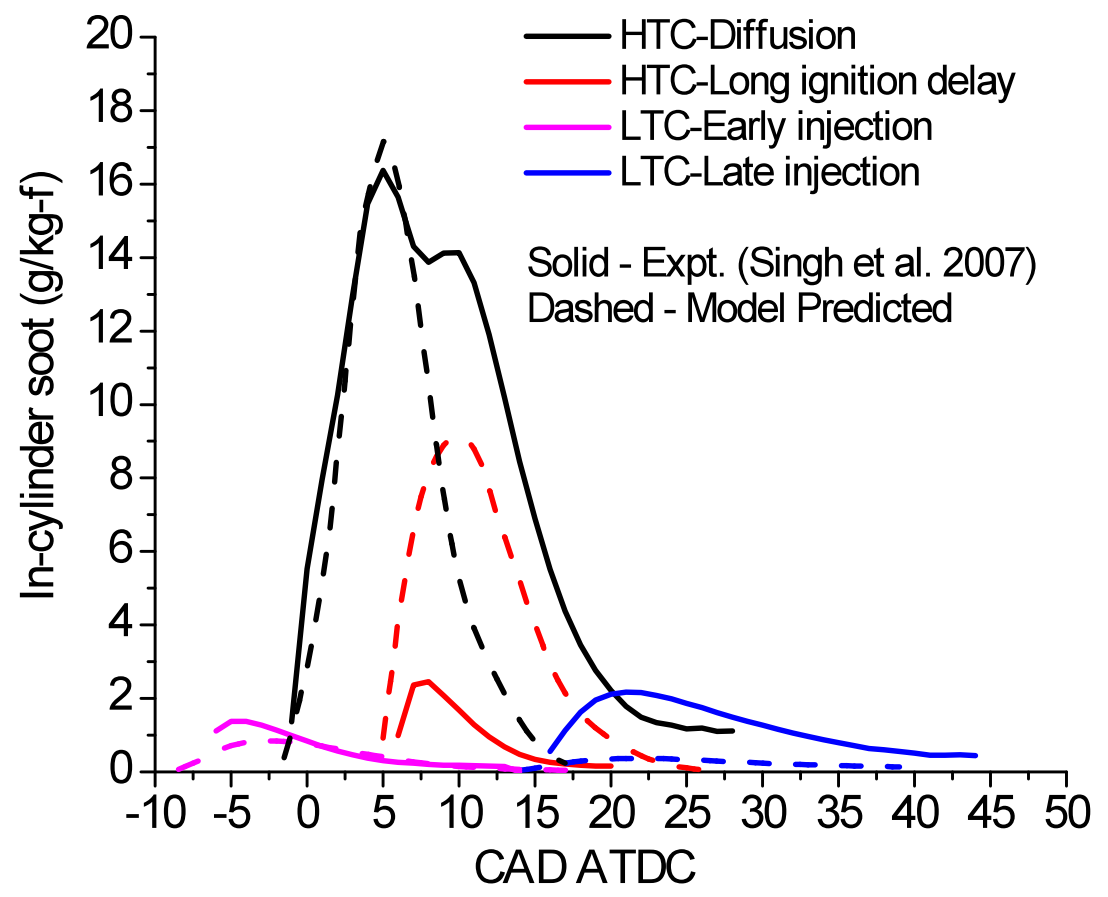

Figure 9: Model predicted total in-cylinder soot histories as compared to the two-color experiments for four different combustion strategies. 

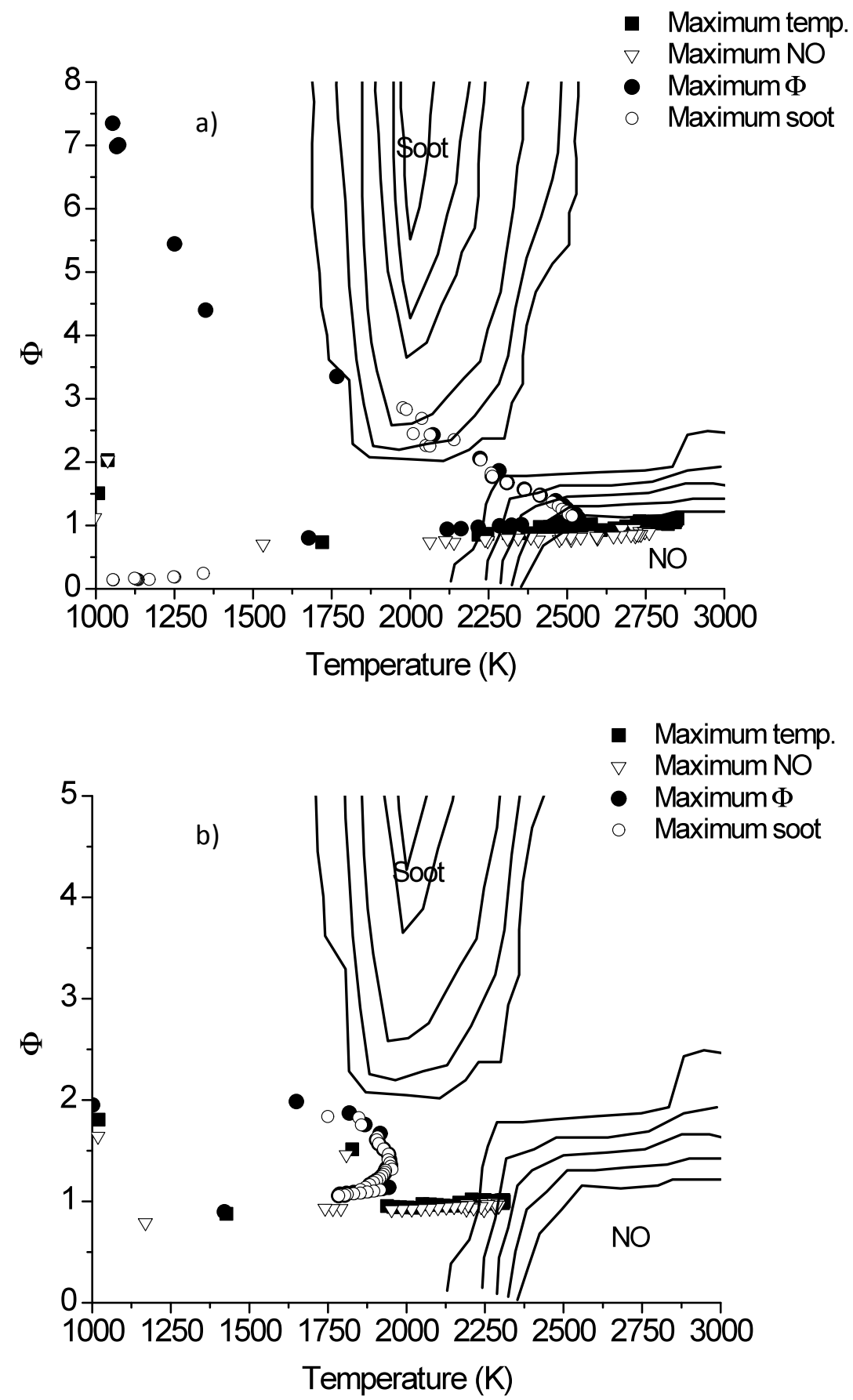

Figure 10: Transient $\Phi-\mathrm{T}$ map for a) HTC diffusion combustion and b) LTC early injection over a CA sweep. The $\Phi$-T contours are the generalized $\Phi$-T contours from Figure 1 


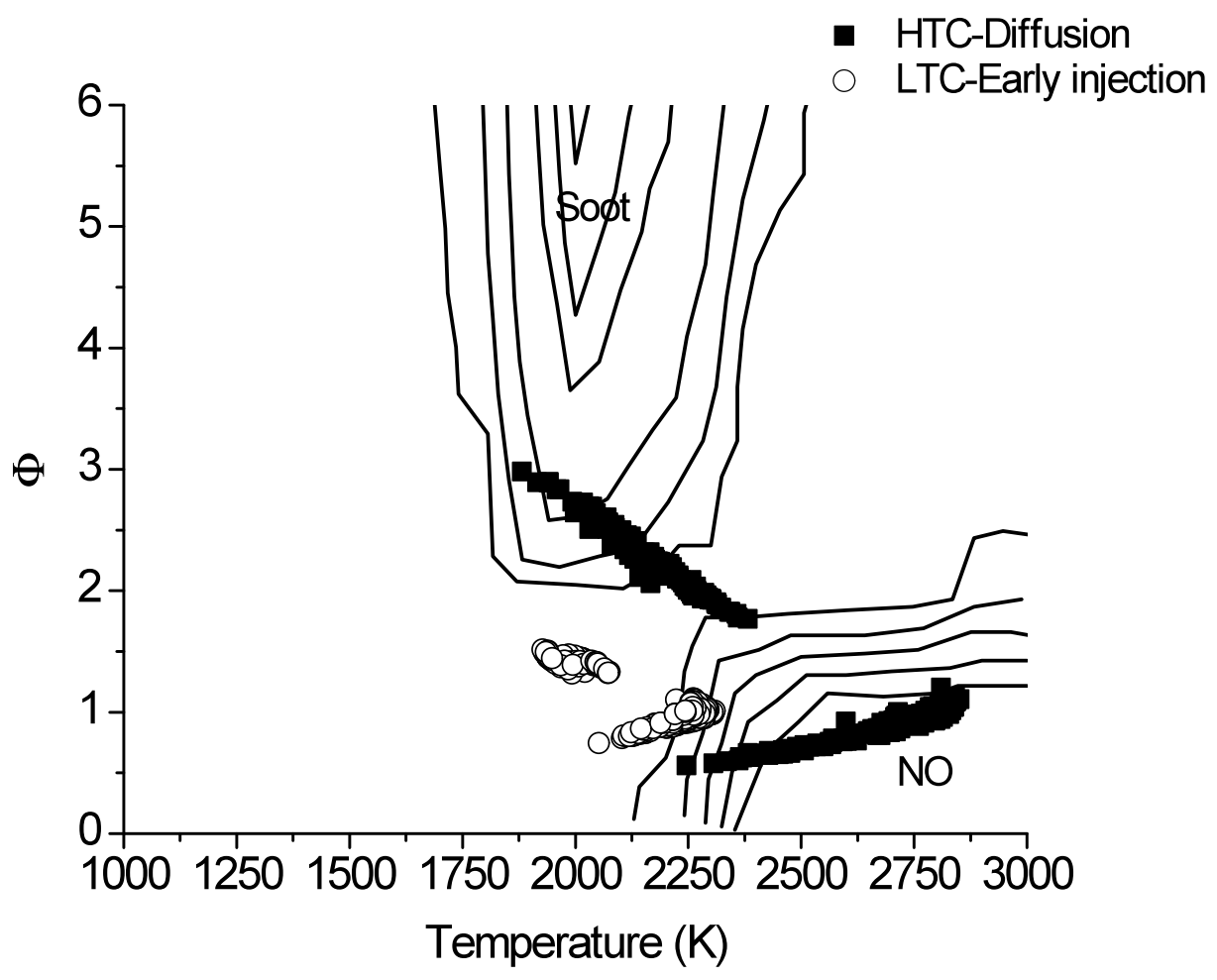

Figure 11: Comparison of the operating regimes of HTC diffusion and LTC early injection in the $\Phi-\mathrm{T}$ map at 4 and -4 CA ATDC, respectively. The $\Phi$-T contours are the generalized $\Phi-\mathrm{T}$ contours from Figure 1 

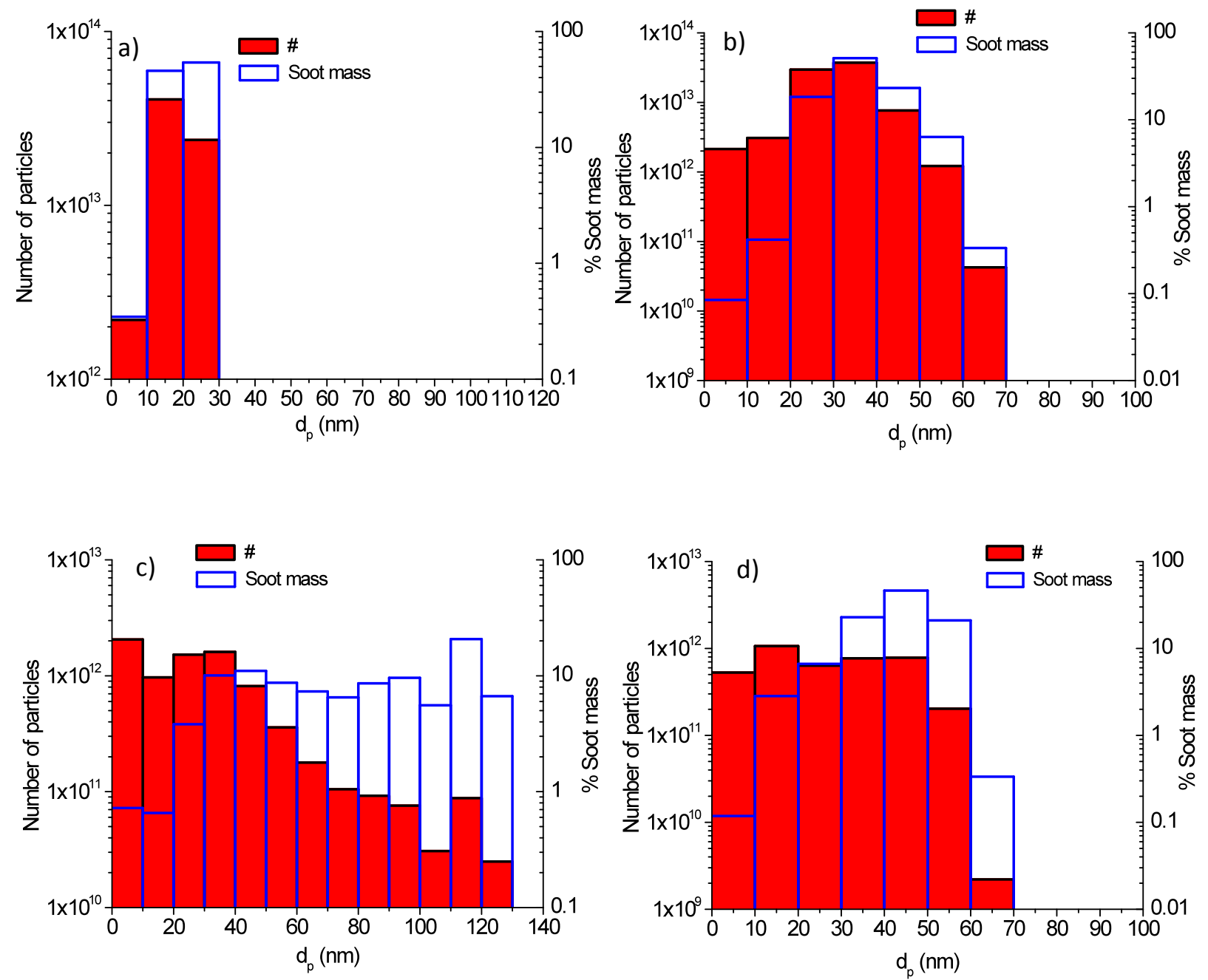

Figure 12: Histograms of $d_{p}$ vs. number of particles and $d_{p}$ vs. soot mass at a) CAD ATDC $\left.=0, b\right)$ CAD $\mathrm{ATDC}=5, \mathrm{c}) \mathrm{CAD} \mathrm{ATDC}=10$ and d) $\mathrm{CAD} \mathrm{ATDC}=20$ for HTC condition. 

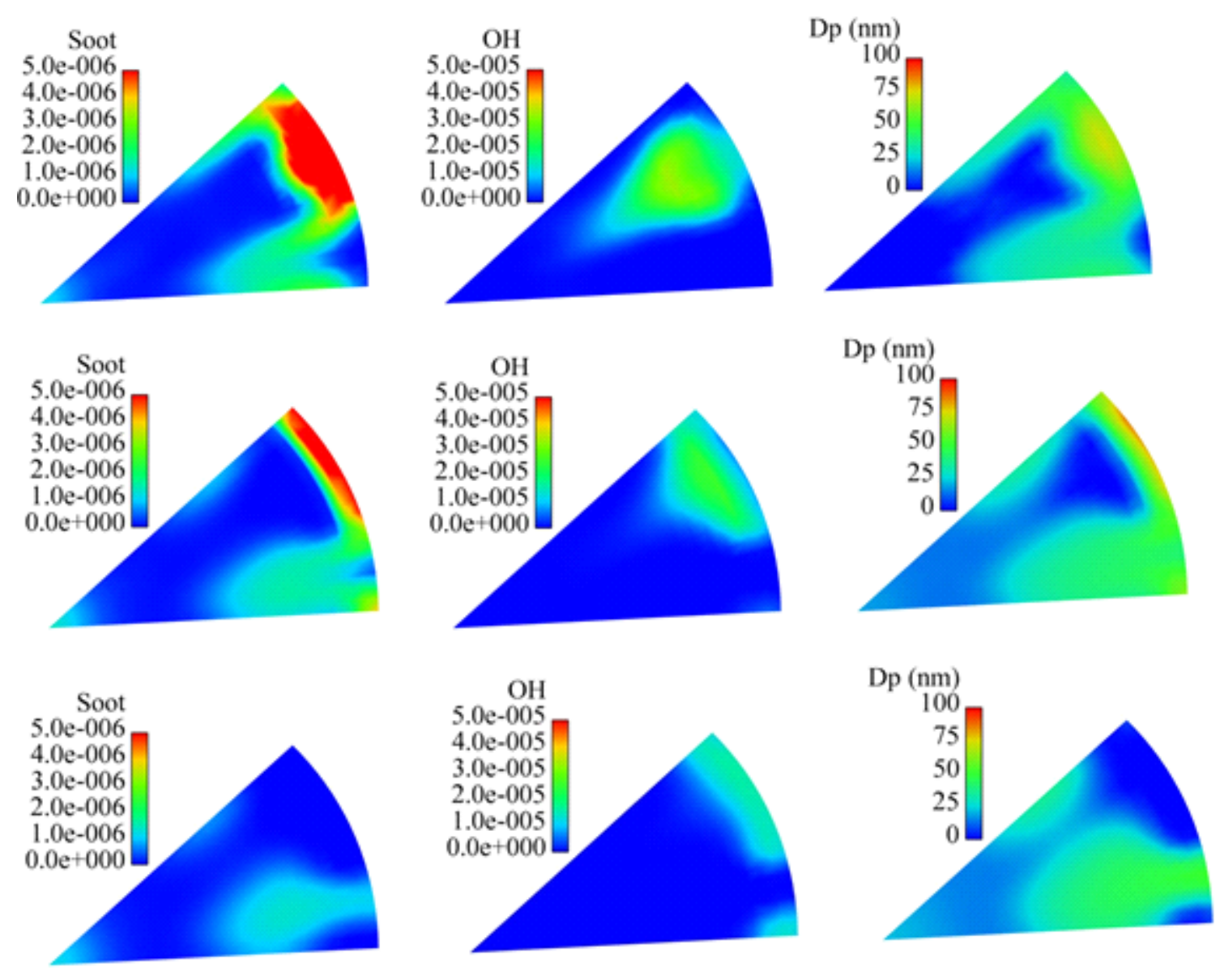

Figure 13: Contours of soot and OH species density $\left(\mathrm{g} / \mathrm{cm}^{3}\right)$, and $\mathrm{d}_{\mathrm{p}}(\mathrm{nm})$ at $10 \mathrm{CAD}$ ATDC (top row), 15 CAD ATDC (center row) and 20 CAD ATDC (bottom row). The circumferential edges represent the liner. 

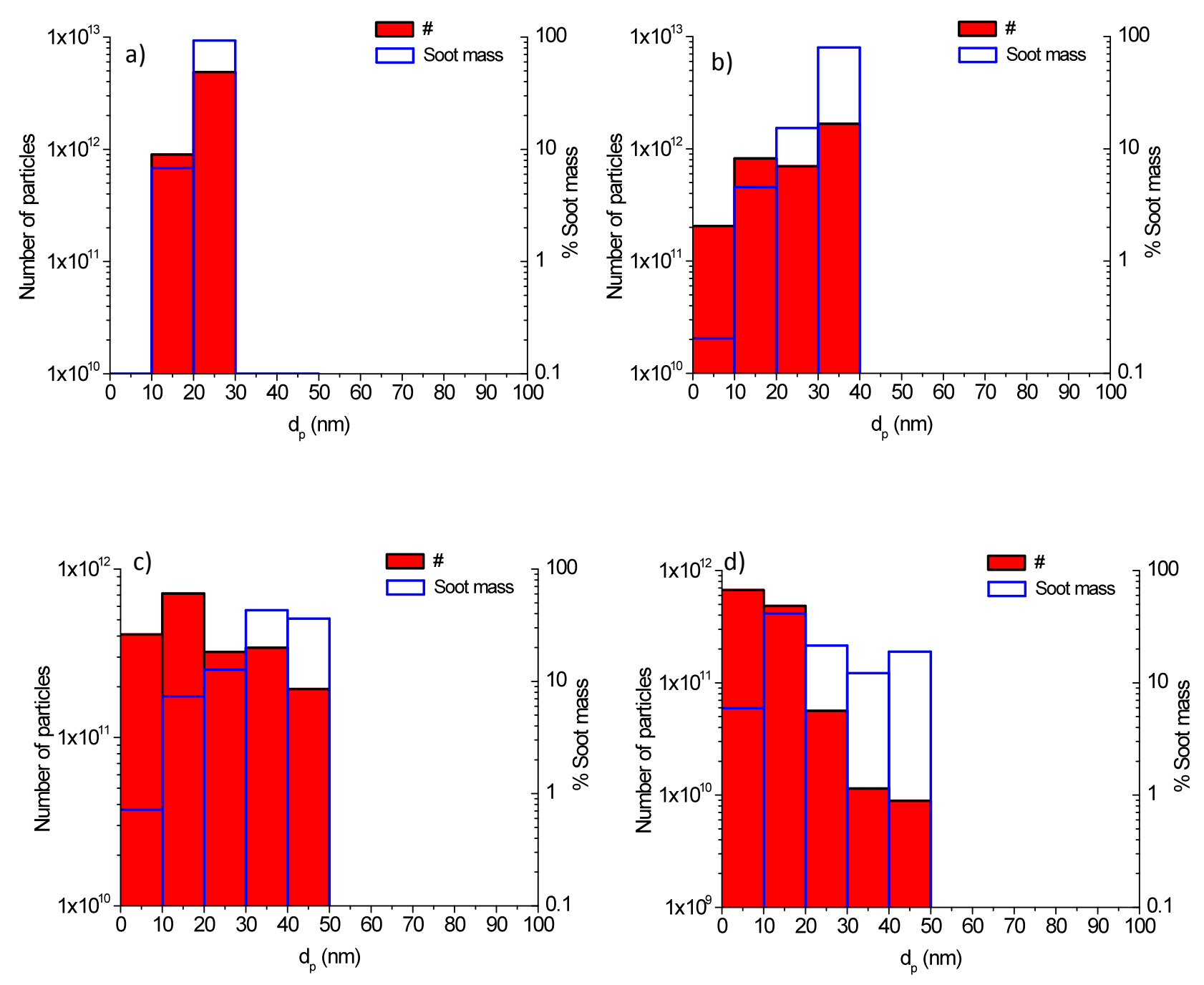

Figure 14: Histograms of $d_{p}$ vs. number of particles and $d_{p}$ vs. soot mass at a) CAD ATDC $=-5$, b) CAD $\mathrm{ATDC}=0, \mathrm{c}) \mathrm{CAD} \mathrm{ATDC}=5$, and d) $\mathrm{CAD} \mathrm{ATDC}=20$ for $\mathrm{LTC}$ condition. 

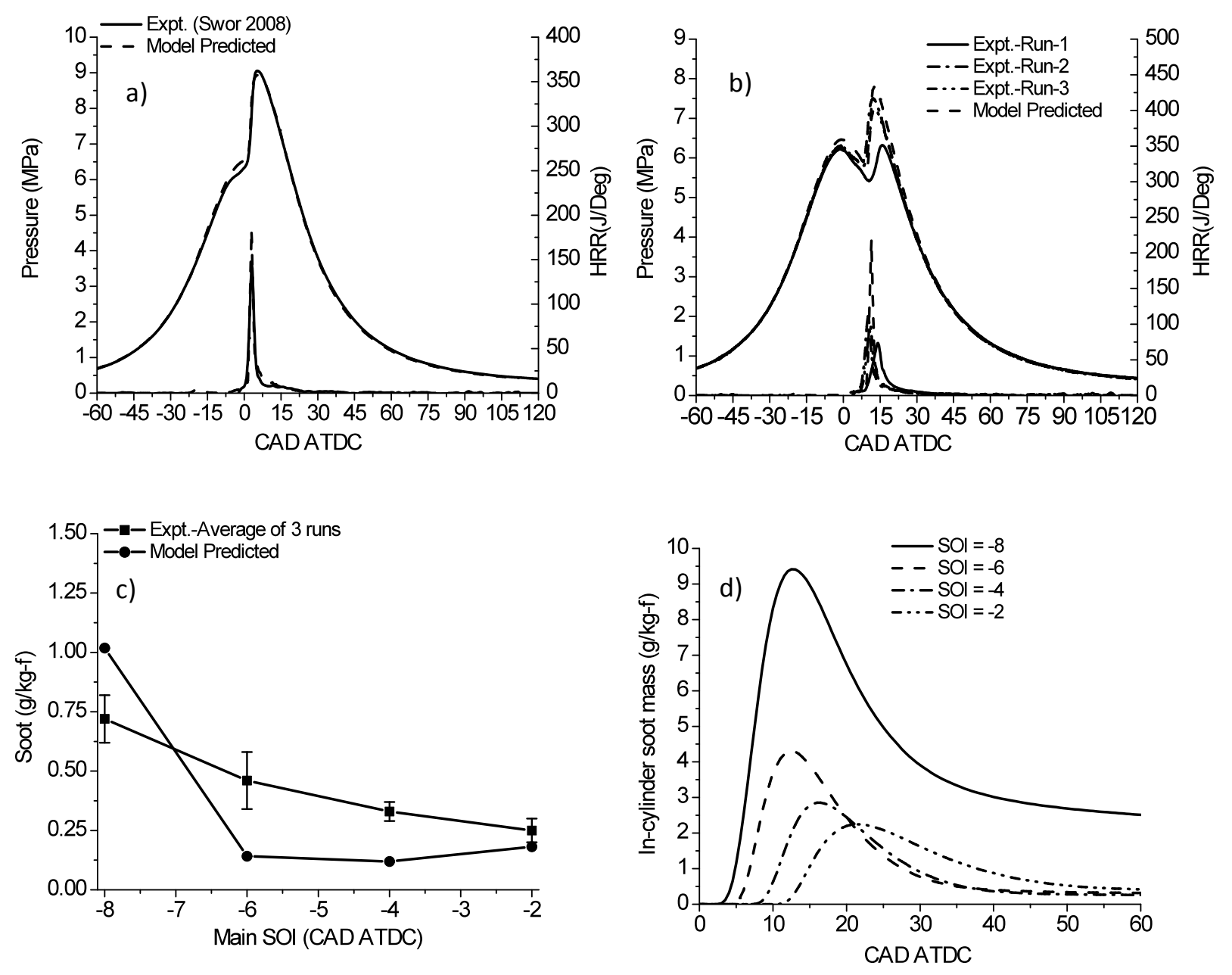

Figure 15: Model predictions of a) pressure and heat release rate at SOI $=-8$ CAD ATDC, b) pressure and heat release rate at $\mathrm{SOI}=-2 \mathrm{CAD}$ ATDC, c) EVO soot mass as compared to experiments and d) In-cylinder soot formation and oxidation histories. 

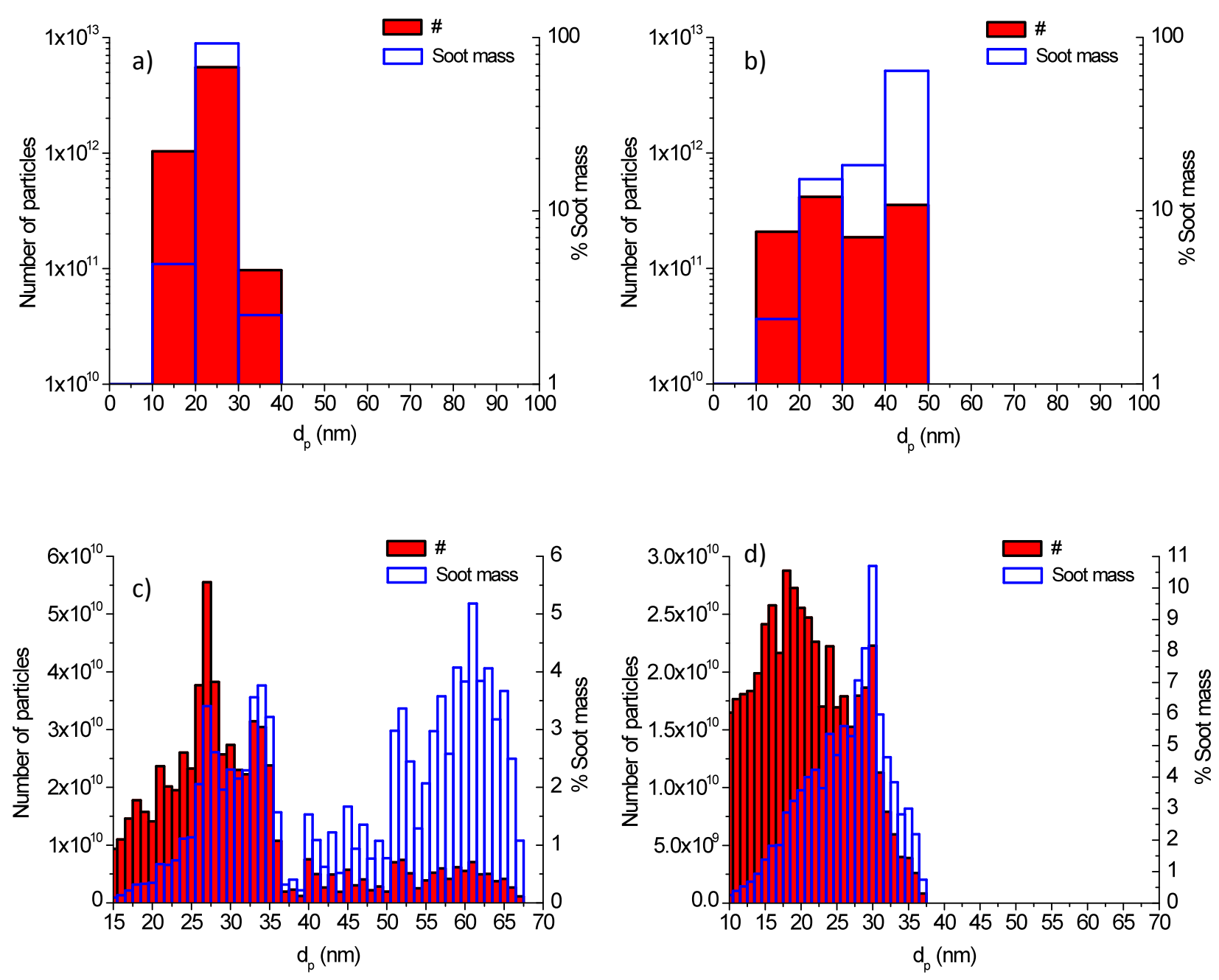

Figure 16: Histograms of $d_{p}$ vs. number of particles and $d_{p}$ vs. soot mass at a) CAD ATDC $=10$ for SOI

$=-8 \mathrm{CAD}$ ATDC, $\mathrm{b}) \mathrm{CAD}$ ATDC $=40$ for $\mathrm{SOI}=-8 \mathrm{CAD}$ ATDC, $\mathrm{c})$ CAD ATDC $=112(\mathrm{EVO})$ for SOI

$=-8 \mathrm{CAD}$ ATDC, and $\mathrm{d}) \mathrm{CAD} \mathrm{ATDC}=112(\mathrm{EVO})$ for $\mathrm{SOI}=-2 \mathrm{CAD} \mathrm{ATDC}$ 
Table 1: SANDIA n-heptane constant volume spray chamber combustion conditions.

\begin{tabular}{|c|c|c|c|c|}
\hline Vol. $\% \mathrm{O}_{2}$ & Vol. $\% \mathrm{~N}_{2}$ & Vol. $\% \mathrm{CO}_{2}$ & Vol. $\% \mathrm{H}_{2} \mathrm{O}$ & $\begin{array}{c}\text { Ambient density }(\rho)- \\
\mathrm{kg} / \mathrm{m}^{3}\end{array}$ \\
\hline 21 & 69.33 & 6.11 & 3.56 & 14.8 \\
\hline 15 & 75.15 & 6.22 & 3.63 & 14.8 \\
\hline 12 & 78.07 & 6.26 & 3.65 & 14.8 \\
\hline 10 & 80.00 & 6.33 & 3.67 & 14.8 \\
\hline 8 & 81.95 & 6.36 & 3.69 & 14.8 \\
\hline 15 & 75.15 & 6.22 & 3.63 & 30.0 \\
\hline 12 & 78.07 & 6.26 & 3.65 & 30.0 \\
\hline 10 & 80.00 & 6.33 & 3.67 & 30.0 \\
\hline 8 & 81.95 & 6.36 & 3.69 & 30.0 \\
\hline
\end{tabular}

Ambient temp. $(\mathrm{T})=1000 \mathrm{~K}$, nozzle diameter $(\mathrm{d})=0.1 \mathrm{~mm}$, injection profile - top-hat, injection pressure $=$ 1500 bar, fuel $=$ n-heptane, injection temperature $\left(T_{\text {inj }}\right)=373 \mathrm{~K}$. 
Table 2: SANDIA diesel constant volume spray chamber combustion conditions

\begin{tabular}{|c|c|c|c|}
\hline Inj. pressure (Mpa) & Nozzle dia. $(\mu)$ & Inj. quantity $(\mathrm{mg})$ & Inj. time $(\mathrm{ms})$ \\
\hline 140 & 50 & 11.9 & 5.9 \\
\hline 140 & 71 & 39.8 & 4.7 \\
\hline 140 & 180 & 14.7 & 5.4 \\
\hline 140 & 100 & 7.5 & 4.9 \\
\hline 40 & 100 & 11 & 5.1 \\
\hline 90 & 100 & 16.2 & \\
\hline
\end{tabular}

Ambient temp. $(\mathrm{T})=1000 \mathrm{~K}, 21 \% \mathrm{O}_{2}$, ambient density $(\rho)=14.8 \mathrm{~kg} / \mathrm{m}^{3}$, injection profile - top-hat, fuel $=\# 2$ diesel with $33.8 \%$ by vol. aromatics, injection temperature $\left(\mathrm{T}_{\mathrm{inj}}\right)=436 \mathrm{~K}$. 
Table 3: Sandia Cummins N14 optical engine conditions.

\begin{tabular}{|c|c|c|c|c|}
\hline Parameters & $\begin{array}{c}\text { High } \\
\text { temperature } \\
\text { diffusion } \\
\text { combustion }\end{array}$ & $\begin{array}{l}\text { High temperature } \\
\text { premixed } \\
\text { combustion }\end{array}$ & $\begin{array}{l}\text { Low temperature } \\
\text { early injection }\end{array}$ & $\begin{array}{c}\text { Low temperature } \\
\text { late injection }\end{array}$ \\
\hline Ambient vol. $\mathrm{O}_{2} \%$ & 21 & 21 & 12.7 & 12.7 \\
\hline SOI ATDC & -7 & -5 & -22 & 0 \\
\hline Intake press. (MPa) & 0.233 & 0.192 & 0.214 & 0.202 \\
\hline Intake temp. (C) & 111 & 47 & 90 & 70 \\
\hline Injected fuel (mg) & 61 & 61 & 56 & 56 \\
\hline Inj. Pressure (bar) & 1200 & 1200 & 1600 & 1600 \\
\hline IMEP (bar) & 4.4 & 4.5 & 3.9 & 4.1 \\
\hline
\end{tabular}


Table 4: GM metal engine operating conditions

\begin{tabular}{|c|c|}
\hline$\%$ EGR & 52 \\
\hline First SOI (CAD ATDC) & -51 \\
\hline Main SOI (CAD ATDC) & $-8,-6,-4,-2$ \\
\hline Intake press. (MPa) & 0.162 \\
\hline Intake temp. (C) & 60 \\
\hline Fuel in first pulse (mg) & 2.07 \\
\hline Fuel in second pulse (mg) & $11-11.5$ \\
\hline First injection pressure (bar) & 300 \\
\hline Second injection pressure (bar) & 1200 \\
\hline IMEP (bar) & 5.5 \\
\hline
\end{tabular}

